\title{
Application of vulnerability modeling techniques in groundwater resources management: a comparative study
}

\author{
Kehinde Anthony Mogaji ${ }^{1,2}$
}

Received: 13 March 2018 / Accepted: 19 July 2018 / Published online: 28 July 2018

(c) The Author(s) 2018

\begin{abstract}
The sustainability management of groundwater resource globally is challenged by its vulnerability to pollution resulting from anthropogenic activities. In order to address this problem, the DRASTIC index model (DIM) method among the existing vulnerability modeling techniques is commonly used. OWA-DRASTIC index model (ODIM) technique is another recently developed method for the same task. This study investigated the application of these vulnerability-biased modeling methods in a multi-faceted geologic setting at Perak Province, Malaysia with the view of establishing their efficiencies. The models considered seven pollution potential conditioning factors (PPCFs) obtained from difference data sources. Applying the GIS-based multi-criterial algorithm of these models, the PPCFs were related for developing multi-parameters-based vulnerability index model equations. Groundwater vulnerability to pollution index (GVPI) maps was produced from the synthesized estimated results of the applied multi-parameters-based vulnerability index model equations. The reliability of the produced GVPI maps was established using analyzed groundwater quality data results. The obtained prediction accuracy results for the ODIM-based GVPI map and DIM-based GVPI map are 85.71 and 64.29\%, respectively. Besides, the regression coefficient results obtained from the spatially estimate from the DIM and ODIM' vulnerability index's values relationship with the $\mathrm{pH}$ and manganese concentrations give 83 and $85 \%$ for the ODIM technique and 68 and $63 \%$ for the DIM technique, respectively. The overall results indicated that the applied ODIM method in the area is a better alternative to the conventional DIM method. The produced GVPI maps can be useful to regional planners and environmental managers entrusted with the protection of groundwater resource.
\end{abstract}

Keywords Groundwater vulnerability · ODIM · Physio-chemical parameters · GVPI · DIM

\section{Introduction}

The susceptibility of groundwater to pollution is a consequence of a finite combination of different factors ranging from the variation in hydrogeological settings and human activities whose togetherness often formed dynamic system (Pathak et al. 2014; Pradhan et al. 2013). These interrelated factors interact in a manner by which the quality monitoring of groundwater system could be predicted. This corroborated with the findings of Samake et al. (2011), whose study has documented that through evaluating the interrelationship

Kehinde Anthony Mogaji

mogajikehindeantony@gmail.com

1 Department of Applied Geophysics, Federal University of Technology, P.M.B. 704, Akure, Nigeria

2 School of Physics, Universiti Sains Malaysia, 11800 Penang, Malaysia between such factors' derived parameters, the outlining of areas that are more susceptible to contamination than others has been feasible. Meanwhile, it is important to note that the term groundwater vulnerability stands for the tendency or likelihood for contaminants to reach a specified position in the groundwater system after introduction at some location above the uppermost aquifer (Jessica and Sonia 2009; National Research Council 1993). This thus implies that the concept of evaluating risk to groundwater fittingly described groundwater vulnerability (Nobre et al. 2007). Furthermore, studies had have it that due to prominent occurrence of hydrogeological setting variation in the subsurface, most areas aquifer that housed groundwater are usually unconfined and highly permeable, thereby causing their high vulnerability to surface contamination (Javadi et al. 2011a, b). A close examination and identification of spatial mapping of these possible vulnerable zones to contamination via developing vulnerability predictive model are 
vital means of getting continuous supply of quality water even at regional scale. According to Anirban et al. (2016), the subscribing to vulnerability assessment is an important yardstick for groundwater resources management particularly to monitor and control the future adverse effect of the unavoidable anthropogenic activities at/or near the earth's surface. For accurate assessment of groundwater vulnerability, several methods have been investigated including the process-based method, the statistical methods and the overlay and index methods. The pros and cons of these methods have been reported in the studies of Jessica and Sonia (2009), and Pradhan et al. (2013). The overlay and index methods among these aforementioned methods are relatively simple and often pave ways for easy combination of different parameters' themes through allocation of numerical index. The renown of this index methods that have been investigated for vulnerability prediction in the field of groundwater hydrology with attractive results are such as DRASTIC, GOD, AVI and SINTACS (Aller et al. 1987; Neshat et al. 2014; Foster 1987; Van Stemproot et al. 1993; Daly and Drew 1999).

In view of the above discussed vulnerability assessment methods, the literature had established that the overlay and index methods had received more attentions in the development of tools credible for the protection of groundwater resource than the others. Among the aforementioned overlay and index methods, the most popular and the widely applied technique across the globe is the DRASTIC index model (DIM) (Al-Abadi et al. 2017; Plymale and Angle 2002; Fritch et al. 2000; Yuan et al. 2006; Huan et al. 2012; Naqa et al. 2006; Javadi et al. 2011a; Mimi et al. 2012; Pacheco and Sanches Fernandes 2012). In applying the DRASTIC method effectively, seven pollution potential conditioning factors (PPCFs) often derived from data sources that are diverse in nature include: depth of water table $(D)$, net recharge $(R)$, aquifer media $(A)$, soil media $(S)$, topography (slope) $\{T\}$, impact of vadose zone $(I)$ and hydraulic conductivity of the aquifer $(C)$ are often considered. With the application of the established DRASTIC model's algorithm, these PPCFs' themes have been synthesized to produce appealed vulnerability prospecting model map usable in environmental decision-making process. But then, this vulnerability method, however, has number of shortcomings including: the lack of ability to process and manage the large volumes of data, it has no capability of accounting for the spatial heterogeneities associated with the systems of natural resources, its assigning weights and rating values on the PPCFs themes is arbitrarily, the index lack functionality of controlling uncertainties that are often aroused due to fuzzy problem associated with groundwater vulnerability assessment, and moreover, the vulnerability indices of the input variables in this model are not continuous. One of the consequences of these limitations particularly the latter factor is such that the final output of DRASTIC index does not reflect the resultant effect of any missing data etc. Sequel to these aforementioned weaknesses of DRASTIC model, several researchers have devised different means of improving the model's performance (Thirumalaivasan et al. 2003; Dixon 2005; Antonakos and Lambrakis 2007; Ckakraborty 2007; Pathak et al. 2014; Pradhan et al. 2013; Mogaji et al. 2014; Nobre et al. 2007; Chen et al. 2013; Singh et al. 2015; Nerantzis and Konstantinos 2015; Wang et al. 2012; Biswajeet and Pradhan 2104; Boris et al. 2016; Kumar et al. 2017; Issoufou and Defourny 2016; Sadeghfam et al. 2016). However, few of these DRASTIC model enhancement studies have quantitatively evaluated the efficiency of their improved model output versus the conventional DRASTIC model result.

In the recent study of Mogaji et al. (2014), the ordered weighted average-DRASTIC (OWA-DRASTIC) was proposed. The approach is an hybrid model where the principle of OWA multi-criteria evaluation technique is driven by the data input from the DRASTIC model theory of assessing vulnerability. The proposed model incorporates user's decision strategies into DRASTIC model technique using OWA operators which thus give an excellent insight into ranking of criteria and addressing uncertainty from their interaction. More importantly, the OWA-DRASTIC model has ability to provide leverage for controlling the level of uncertainties associated with different decision alternatives and risk taking (i.e., optimistic, pessimistic and neutral). The managing decisional uncertainty in multi-criteria prediction potentiality is a very good attribute of the OWA method (Yager 1988; Yager 1996; Nadi and Delavar 2011; Gorsevski et al. 2012). Another strength of this model is that it can efficiently generate a set of diverse solutions that are essential in environmental decision making by changing the set of ordered weights. Thus, its applications in solving a variety of spatial problems including: land-use suitability problems (Chen et al. 2009; Malczewski 2006b), site-selection problems (Rinner and Raubal 2004) have been documented.

In this study, the applicability of vulnerability modeling techniques to groundwater resources management in a comparative analysis is investigated. The applied modeling techniques include the DRASTIC model and the recently developed OWA-DRASTIC model. These models use multiple PPCFs sets in assessing the groundwater quality in a multifaceted geologic setting at Perak Province, Malaysia. The specific objectives of this study are as follows: (1) produce the groundwater vulnerability to pollution index (GVPI) map through DRASTIC model index, (2) produce the groundwater vulnerability to pollution index (GVPI) map through OWA-DRASTIC model index, (3) validated the produced GVPI maps using the groundwater quality analyzed results obtainable in the area and (4) analyzed the validation results to evaluate the efficiency of the models with the view of 
establishing which one is best efficient for environmental decision making toward effective groundwater resources management and sustainability.

\section{Materials and method}

Presented in Fig. 1 is the models method and the flowchart used in the study.

\section{Study area}

The study according to Mogaji et al. (2014) has provided information on the geography, geology and the hydrogeology of the investigated area whose zoning region is in the southern Perak Province, Malaysia (Fig. 2). However, the multi-faceted geological characteristics of the area have established generally, that the area's underlain aquifers are more of confined aquifer to unconfined aquifer. This indeed supported why there has been no record of groundwater contamination and pollution problems in the occupied segment of the study area. However, the tendency of an area underlain groundwater containing medium (aquiferous unit) is largely a function of the thickness of the aquifer confining layer which varies spatially. Moreover, in accordance with Singh et al. (2015) and De Vries and Simmer (2002), the activities of weathering of source rocks and recharge from water bodies to aquiferous units on regional scale often contaminate the occupying groundwater through discharge of toxic metals etc. Thus, the need arise to put in place basis preventive measure policies to preserve this precious natural resources through regional vulnerability assessment approach.

\section{Dataset used}

The data used in this study were obtained from various data sources that are readily available as listed in Table 1 and presented in Fig. 1. The selection of these data types was based on the data requirement for the DRASTIC method theory as established by the United States Environmental Protection Agency (USEPA). Such data type has been used to classify the pollution potential of aquifers (Aller et al. 1987). Possible pollution potential conditioning factors (PPCFs) are derived from these data types that served as the input to drive the renowned DRASTIC model index algorithm (Table 1 and Fig. 1). The highlight of these PPCFs' thematic layers preparation is reported in these subsections.

\section{The data types processing and pollution potential conditioning factors (PPCFs) thematic maps preparation}

In accordance with Table 1 and Fig. 1, the data types were obtained from different sources. The geospatial approach for their thematic preparation is as detailed in Mogaji et al. (2014). However, for the acquired RS data, i.e., ASTER DEM data, mosaicking and georeferencing using ArcGIS 10.1 and ENVI 4.7 software were carried out. Furthermore, the acquired surface soil map was scanned, imported into ArcGIS 10.1 and georeferenced to the UTM/WGS84 projection system. The records of climate data (rainfall amount) at each observed station were analyzed using MS-Excel software package. The acquired $2 \mathrm{D}$ resistivity imaging data in the area were processed and inverted using the RES2DINV software (Mogaji and Lim 2018). Following through the above painstaking processes, the obtained data types (Table 1) were used to produce PPCFs' thematic maps such as depth to water table $(D)$, recharge rate $(R)$, aquifer media $(A)$, soil media $(S)$, topography $(T)$, impact of vadose zone $(I)$ and hydraulic conductivity (C). Figure 3 presents the PPCFs' thematic maps prepared in GIS environment. The analysis and the interpretation of these Fig. 3 themes are qualitatively reported in Table 2. The hydrologic significance and the contributions of these PPCFs parameters in groundwater vulnerability modeling/analysis have been scientifically established (Anirban et al. 2016; Pradhan et al. 2013). Nobre et al. 2007 Doumouya et al. 2012; Samake et al. 2011). The harnessing of these factors weightage influence using different vulnerability methods' algorithm has been evaluated (Thirumalaivasan et al. 2003; Dixon 2005; Antonakos and Lambrakis 2007; Mogaji 2017; Razandi et al. 2015; Falah et al. 2016; Naser et al. 2016).

\section{Description of the models}

\section{DRASTIC index model (DIM) theory}

The scientific basis viz-a-viz the theory and the established algorithm for the DIM technically adapt the weight linear combination (WLC) mathematically, where the weight, the range and the rating of imputes are often expressed numerically. The information on the model working principle has been documented in several studies of Sahoo et al. (2016), Mogaji (2017) and Aller et al. (1987). According to Ettazarini and El Mahmouhi (2004), the hydrogeological parameters component for the workability of the model includes: depth to water table $(D)$, net recharge $(R)$, aquifer media $(A)$, soil media $(S)$, topography or slope $(T)$, impact of the vadose zone $(I)$ and hydraulic conductivity $(C)$. With these parameters serving as the imputes in Eq. (1), the parametric evaluation of an index of DRASTIC vulnerability can be determined

$$
\mathrm{DI}=\sum_{i=1}^{m}\left(W_{i} \times R_{i}\right)
$$

where DI, $W_{i}, R_{i}$ and $m$ are the DRASTIC index, weights, ratings and number of the hydrogeological factors, respectively (Aller et al. 1987). 


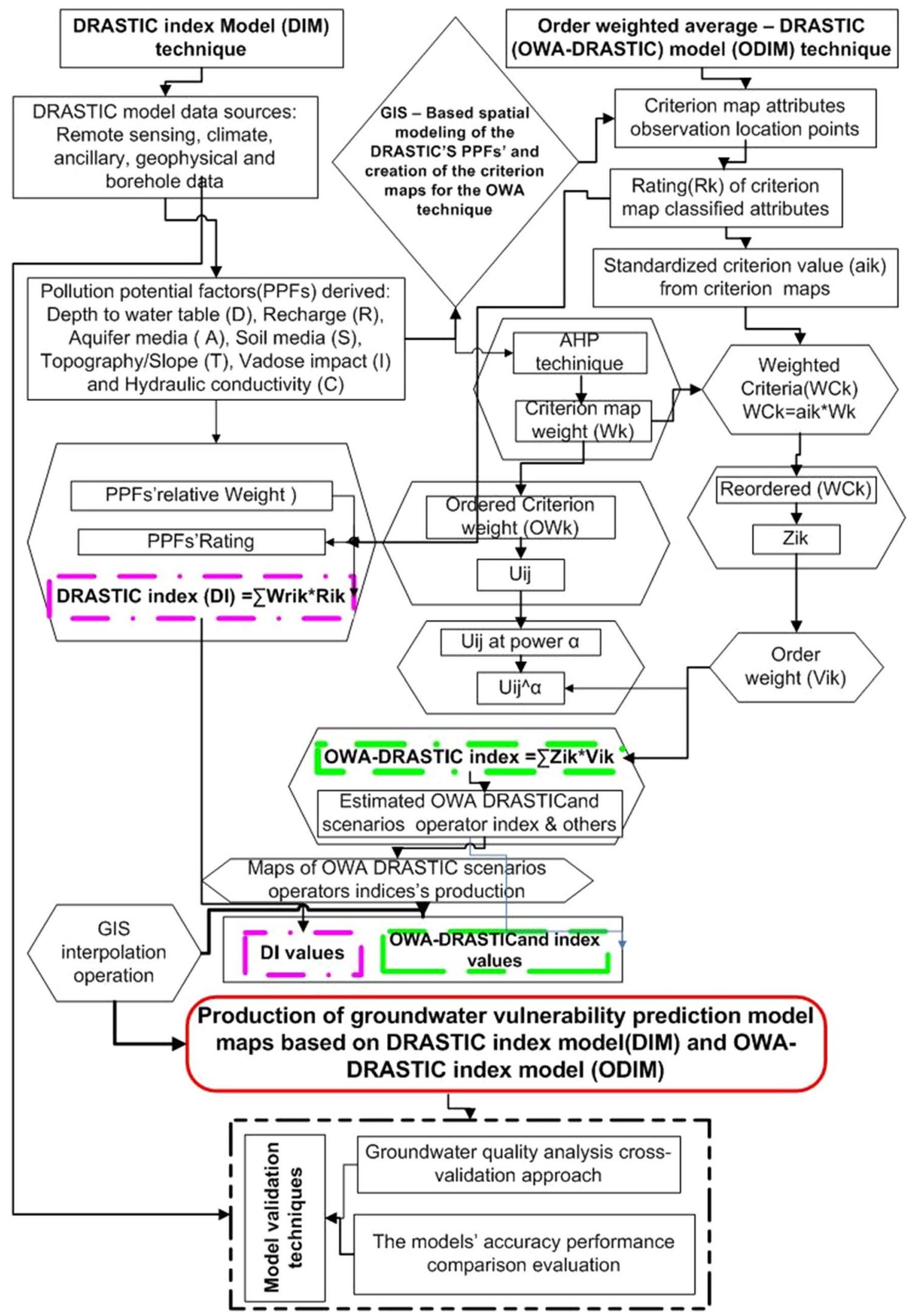

Fig. 1 Methodology flowchart for the comparative study 


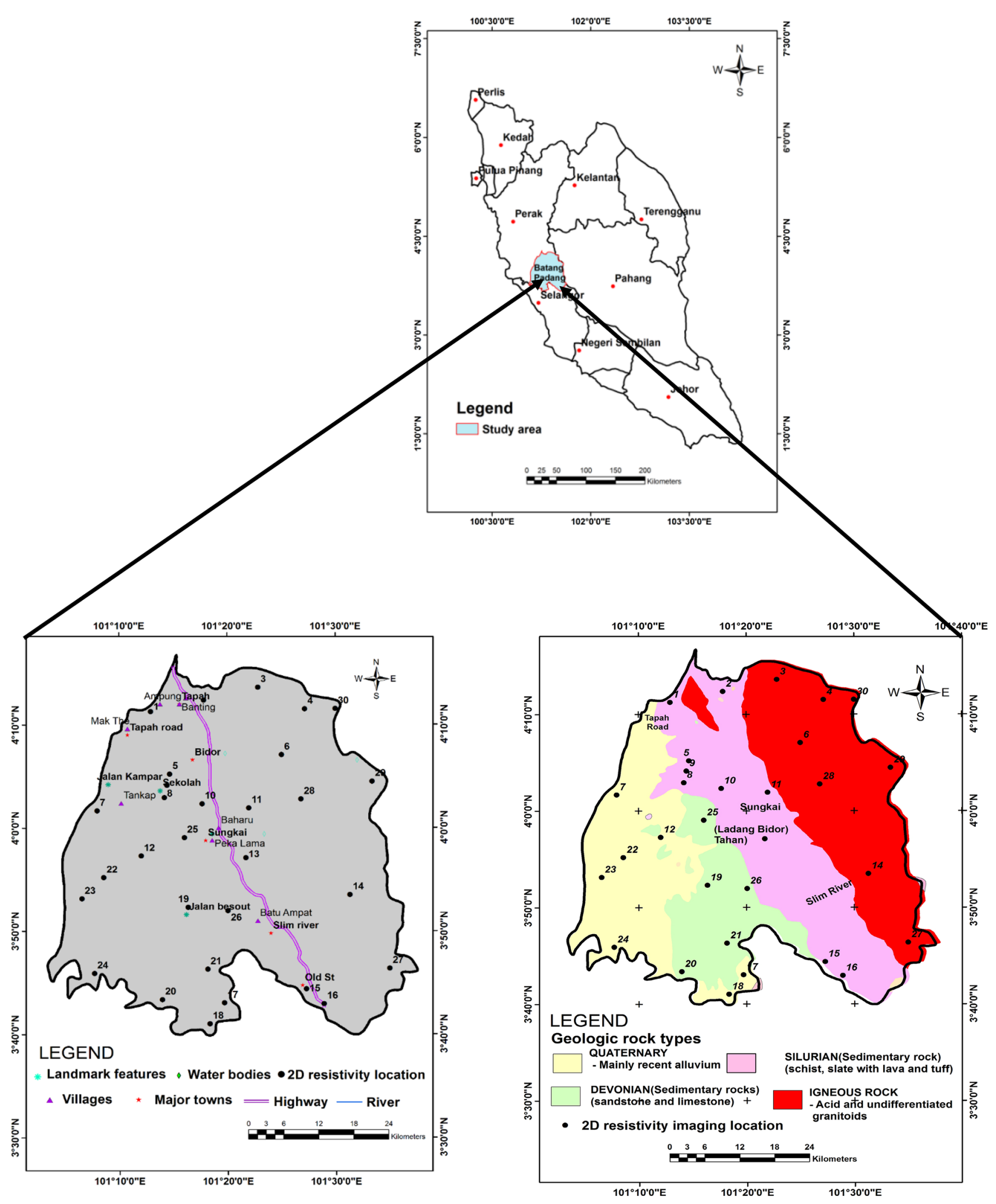

Fig. 2 The study area map and its geological map showing the inset map of Malaysia 
Table 1 Information and sources of data used

\begin{tabular}{llll}
\hline Data type & Detail of data & Format & Output layer \\
\hline Borehole data & $\begin{array}{l}\text { Malaysian Department of Mineral and Geosciences Date } \\
\text { acquired }\end{array}$ & Table and lithology log & Depth to water table $(D)$ \\
Average annual rainfall & $\begin{array}{l}\text { Tropical Rainfall Measuring Mission (TRMM) database } \\
\text { Geophysical data }\end{array}$ & Table & Recharge $(R)$ \\
Soil map & Matang Padang, Perak & Point & Aquifer $(A)$ \\
& Ministry of agriculture Kuala Lumpur, Malaysia(1962) Scale: & Map & Soil type $(S)$ \\
Remote sensing imagery & ASTER DEM data NASA((LP DAAC) Resolution: 30 m & Satellite image & Topography/slope $(T)$ \\
Geophysical data & Batang Padang, Perak & Point & Impact of vadoze zone $(I)$ \\
Borehole data & Malaysian Department of Mineral and Geosciences & Table and lithology log Hydraulic conductivity $(K)$ \\
Data type & Detail of data & Format & Output layer \\
Borehole data & Malaysian Department of Mineral and Geosciences & Table and lithology log Depth to water table $(D)$ \\
\hline
\end{tabular}

\section{Ordered weighted averaging (OWA)-DRASTIC index model (ODIM)}

The OWA-DRASTIC model was burned out of the hybrid product of the DRASTIC model theory and the OWA method theory. This model derived its philosophy from the principles of both DRASTIC model theory and fuzzy function quantifier-guided OWA principle. In the studies of Gorsevski et al. (2012) and Malczewski (2006a), the basics theory guiding the methodology of OWA multi-criteria technique has been reported. The sequential approach for this model as presented in Fig. 1 includes: (1) selection of the causative criteria' and their themes prepared input, (2) standardization of the criterion values $\left(a_{i k}\right)$ from each criterion themes, (3) determination of the criterion weights $\left(W_{k}\right)$ according to the preferences of experts, (4) determination of the reordered weight $\left(Z_{i k}\right)$ and (5) determination of the ordered weights via applying different OWA operators $\left(V_{i k}\right)$. The hybridization of these steps output with the DRASTIC theory algorithm via considering the varying power of fuzzy membership function $\alpha$ parameter gives birth to the OWADRASTIC index model (ODIM) developed.

\section{The application of DRASTIC index model technique to groundwater vulnerability mapping}

The application of DRASTIC index model for assessing groundwater vulnerability in the study area has been painstakingly investigated. The application procedures are better explained using the information provided in Table 2 and Fig. 4. In Table 2, the pollution potential factors' thematic layers (the criterion map), the classes (indicators) and pollution potentiality interpretation are given in columns 1,2 and 3 , respectively. The qualitative rating $(R)$ for the criterion maps (Column 4) gives the interpretation of the ranges of the pollution potentiality (Column 3 ) within each criterion maps. With the rating $(R)$, the criterion maps were ranked based on the order of the map's class influences. The assigned rating scales were in agreement with the approach adopted in the studies of Al-Saud (2010) and Murthy (2000) where rating $(R)$ scales of 1, 2, 3, 4 and 5 are interpreted as very low, low, medium, medium high and high pollution potentiality, respectively. The assigned weights (column 5) are assigned to each of the pollution potential factors 'to indicate their relative importance in contributing toward groundwater vulnerability assessment in the area. To compute for the DRASTIC vulnerability index (DI) values, multi-steps were employed. First, the pollution potential conditioning factors (PPCFs) (for example aquifer media) were selected and prepared for thematic layer. After that, the Fishnet module as rectangular cell of polyline or polygon features in Arc Toolbox was applied to create the centroids of the grid cells for each thematic map in GIS environment where both Long and Lat grid coordinates of the centroids as designed typically in Fig. 4 were observed. This same process was adopted to create criterion map for each of the remaining PPCFs. The attributes of the observed location point (the centroids) reference to the class boundaries of any considered criterion map were interpreted viz-a-viz their corresponding pollution potentiality interpretation (Column 3 ) for the rating $(R)$ scales assignment (Table 2). Considering the determined $R$ and $W$ variables at each criterion map observed location points, the linear additive combination of these variables using Eq. (1), the DRASTIC vulnerability index (DI) value can be estimated.

\section{The application of OWA-DRASTIC index model technique to groundwater vulnerability mapping}

The application of OWA-DRASTIC index model for assessing groundwater vulnerability in the study area encompasses several procedures as mentioned in Sect. 3.2. The details of the implementation of these aforementioned multi-steps are as reported in the studies of Gorsevski et al. (2012), Malczewski (1999), Feizizadeh et al. (2012), Eastman and 

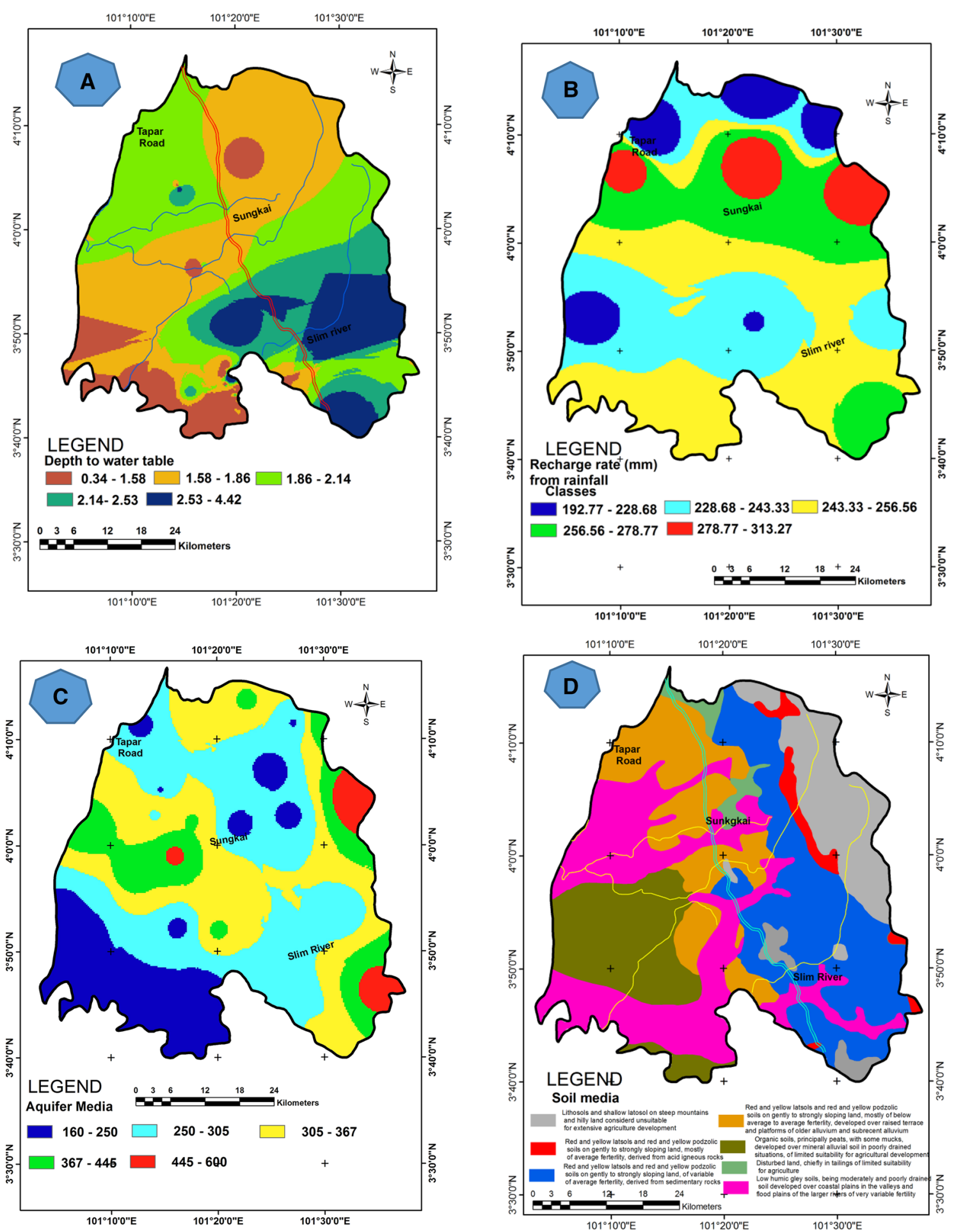

Fig. 3 Pollution potential conditioning factors (PPCFs) for DRASTIC index and OWA-DRASTIC index models: a depth of water, b recharge rate, $\mathbf{c}$ aquifer medial, $\mathbf{d}$ soil type, $\mathbf{e}$ topography (slope $\%$ ), $\mathbf{f}$ impact of vadose zone, $\mathbf{g}$ hydraulic conductivity

Jiang (1996) and Mogaji et al. (2014). According to one of the studies, the criterion weights $\left(W_{k}\right)$ determinations for the PPCFs were based on the applied knowledge expert weighting index technique where the 0.039 consistency ratio (CR) estimated value indicates a good consistency of the judgments of the expert opinion (Adiat et al. 2012; Mogaji et al. 2016). The reordered weight $\left(Z_{i k}\right)$ and the order weights $\left(V_{i k}\right)$ are the other vital components determined for the PPCFs 

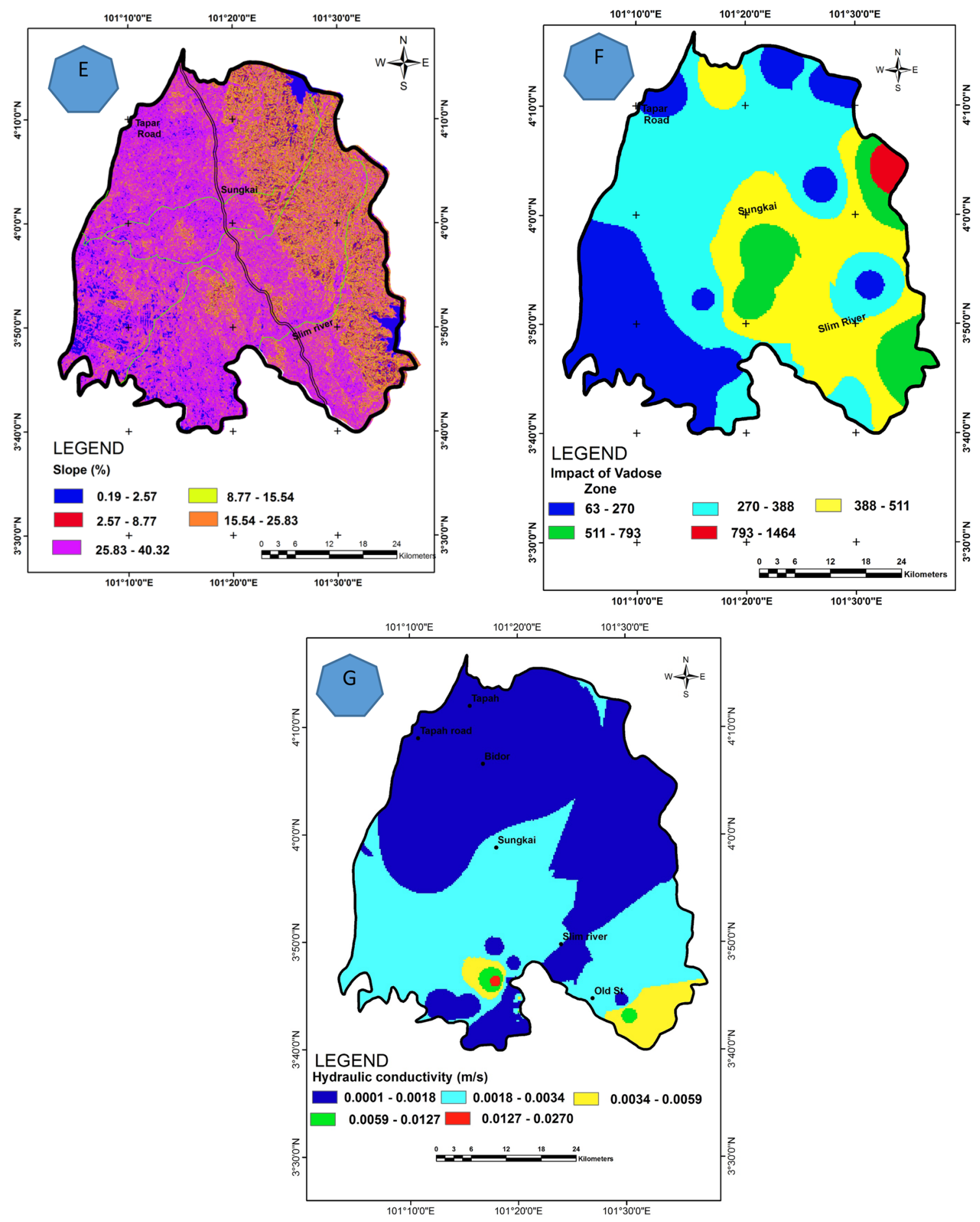

Fig. 3 (continued)

serving inputs using the established mathematical equations. Shown in Tables 3 and 4 are the typical $Z_{i k}$ computation results for $Z_{i k}$ and $V_{i k}$ based on the applied OWA index theory at each of the criterion observed locations of the PPCFs using the template model in Fig. 4.
Using the above determined $Z_{i k}$ and $V_{i k}$ of OWA index theory for the PPCFs and their fussing with the known DRASTIC theory algorithm, the applied OWA-DRASTIC index model is established in Eq. (2).

$$
\begin{aligned}
\text { OWA-DRASTIC }_{i}= & V_{i k D} z_{i k D}+V_{i k R} z_{i k R}+V_{i k A} z_{i k A}+V_{i k S} z_{i k S} \\
& +V_{i k T} z_{i k T}+V_{i k I} z_{i k I}+V_{i k C} z_{i k C}
\end{aligned}
$$


Table 2 The pollution potential conditioning factors (PPCFs) ratings and their weights (Modified after: Atiqur Rahman 2008 and Chen et al. 2013)

\begin{tabular}{|c|c|c|c|c|}
\hline The criterion & Ranges (classes) & $\begin{array}{l}\text { Pollution potentiality for } \\
\text { groundwater vulnerability }\end{array}$ & $\begin{array}{l}\text { Rating } \\
\text { (unstandard- } \\
\text { ized values) }\end{array}$ & $\begin{array}{l}\text { Assigned } \\
\text { weight }\end{array}$ \\
\hline \multirow[t]{5}{*}{ Depth to water $(D)$} & $0.34-1.58$ & High & 5 & 5 \\
\hline & $1.58-1.86$ & Medium high & 4 & \\
\hline & $1.86-2.14$ & Medium & 3 & \\
\hline & $2.14-2.53$ & Low & 2 & \\
\hline & $2.53-4.42$ & Very low & 1 & \\
\hline \multirow[t]{5}{*}{ Recharge rate $(R)$} & $192.77-228.68$ & Very low & 1 & 4 \\
\hline & $228.68-243.33$ & Low & 2 & \\
\hline & $243.33-256.56$ & Medium & 3 & \\
\hline & $256.56-278.77$ & Medium high & 4 & \\
\hline & $278.77-313.27$ & High & 5 & \\
\hline \multirow[t]{5}{*}{ Aquifer media $(A)$} & $160-250 \Omega \mathrm{m}$ (sandy clay/fine sand) & Very low & 1 & 3 \\
\hline & 250-305 $\Omega \mathrm{m}($ sand/gravel) & Medium & 3 & \\
\hline & 305-367 $\Omega \mathrm{m}$ (medium sand/coarse gravel) & Medium high & 4 & \\
\hline & $367-445 \Omega \mathrm{m}$ (weathered sandstone) & Low & 2 & \\
\hline & 445-600 $\Omega \mathrm{m}$ (fractured/jointed sandstone) & High & 5 & \\
\hline \multirow[t]{7}{*}{ Soil media $(S)$} & Lithosol and shallow latosol (steep mountail) & Very low & 1 & 2 \\
\hline & Red and yellow podozolic soil from acid igneous rock & Low & 2 & \\
\hline & $\begin{array}{l}\text { Red and yellow latsols podozolic soil from sedimentary } \\
\text { rocks }\end{array}$ & Medium & 3 & \\
\hline & $\begin{array}{l}\text { Red and yellow latsols podozolic soil from older and sub } \\
\text { recent alluvium }\end{array}$ & Medium high & 4 & \\
\hline & Organic soil-peat and poorly drained & Very low & 1 & \\
\hline & $\begin{array}{l}\text { Low humic gley soil developed in the valley and flood } \\
\text { plain }\end{array}$ & High & 5 & \\
\hline & Agricultural land & Medium high & 4 & \\
\hline \multirow[t]{5}{*}{ Topography (slope) $(T)$} & $0-2.57$ & (Flat) High & 5 & 1 \\
\hline & $2.57-8.77$ & (Undulating) Medium high & 4 & \\
\hline & $8.77-15.54$ & (Rolling) Medium & 3 & \\
\hline & $15.54-25.83$ & (Moderately steep) Low & 2 & \\
\hline & $25.83-40.32$ & (Steep) Very low & 1 & \\
\hline \multirow[t]{5}{*}{ Impact of vadose zone $(I)$} & 63-270 $\Omega \mathrm{m}$ (clay/silty sand) & Very low & 1 & 5 \\
\hline & 270-388 $\Omega \mathrm{m}$ (sand/gravel) & Medium high & 4 & \\
\hline & 388-511 $\Omega \mathrm{m}$ (fissure sandstone/coarse gravel) & High & 5 & \\
\hline & 511-793 $\Omega \mathrm{m}$ (hard sandstone/coarse gravel) & Medium & 3 & \\
\hline & 793-1464 $\Omega \mathrm{m}$ (consolidated/hardrock) & Low & 2 & \\
\hline \multirow[t]{5}{*}{ Hydraulic conductivity $(C)$} & $0.0001-0.0018$ & Very low & 1 & 3 \\
\hline & $0.0018-0.0034$ & Low & 2 & \\
\hline & $0.0034-0.0069$ & Medium & 3 & \\
\hline & $0.0069-0.0127$ & Medium high & 4 & \\
\hline & $0.0127-0.0270$ & High & 5 & \\
\hline
\end{tabular}

\section{Results and discussion}

\section{The DRASTIC index (DI) technique application results}

Table 5 presented the application results of the DRASTIC model technique in mapping the vulnerability prospect in the area. According to Table 5, the records for both the Long and Lat were the center grid coordinates of the observed location depicted in Fig. 4. It was based on the attributes of this location points viz-a-viz their pollution potential degree of classes that the rating $(\mathrm{R})$ scores as earlier discussed were scored. The $W$, on the other hand, is the assigned weight to each of the PPCFs in respect of their degree of importance 


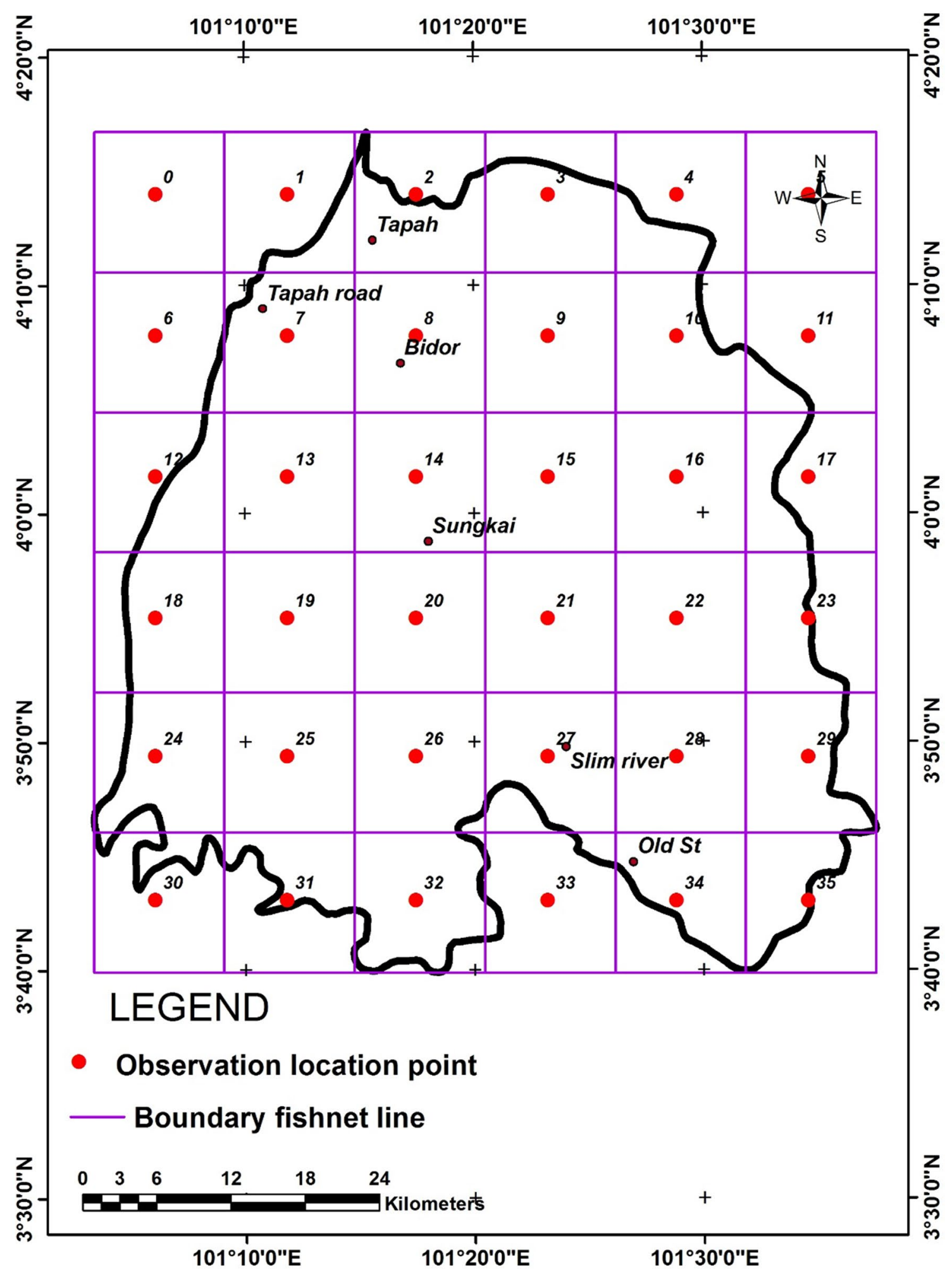

Fig. 4 The centroid and the criterion map conversion template model

in measuring the vulnerability prospect in the area. With the records for both $R$ and $W$ variables, the DRASTIC index (DI) values for each observed locations (Fig. 4) in the area are estimated using Eq. 1. The determined DI values for each location are detailed in column (18) of Table 5. According to the table, the DI values characterizing the study area vary 
Table 3 The selected results of the computed OWA index component weights for some stations in the study area

\begin{tabular}{lllll}
\hline$S / \mathrm{N}$ & Criteria & $a_{i k}$ & $w_{k}$ & $a_{i k} w_{k}$ \\
\hline 1 & $D$ & $\{0.5,0.75,0.5,0.75,0.75,0.75,05]$ & 0.31 & $\{0.16,0.23,0.16,0.23,0.23,0.23,0.16\}$ \\
2 & $R$ & $\{0.5,0.5,0.75,0.75,1,0.75,0.5\}$ & 0.16 & $\{0.08,0.08,0.12,0.12,0.16,0.12,0.08\}$ \\
3 & $A$ & $\{0.25,1,0.5,0.75,0,0.5,1\}$ & 0.08 & $\{0.02,0.08,0.04,0.06,0,0.04,0.08\}$ \\
4 & $S$ & $\{0.5,0,0.75,0.75,0.5,0,1\}$ & 0.04 & $\{0.02,0,0.03,0.03,0.02,0,0.04\}$ \\
5 & $T$ & $\{0.25,0.25,0,0.25,0.75,0.5,0\}$ & 0.02 & $\{0.01,0.01,0,0.01,0.02,0.01,0\}$ \\
6 & $I$ & $\{0.5,0,0.75,1,1,1,0.75\}$ & 0.31 & $\{0.16,0,0.23,0.31,0.31,0.31,0.23\}$ \\
7 & $C$ & $\{0,0,0,0,0,0,0.25\}$ & 0.08 & $\{0,0,0,0,0.02\}$ \\
\hline & & & $u_{i j}$ & $\{0.16,0.23,0.23,0.31,0.31,0.31,0.31\}$ \\
1 & & $D$ & $\{0.31,0.31,0.16,0.08,0.08,0.04,0.02\}$ & $\{0.16,0.08,0.16,0.23,0.23,0.23,0.23\}$ \\
2 & $R$ & $\{0.31,0.16,0.08,0.08,0.04,0.02,0.31\}$ & $\{0.08,0.08,0.12,0.12,0.16,0.16,0.12\}$ \\
3 & $A$ & $\{0.08,0.08,0.04,0.02,0.31,0.31,0.16\}$ & $\{0.02,0.01,0.04,0.06,0.02,0.02,0.04\}$ \\
4 & $S$ & $\{0.08,0.04,0.02,0.31,0.31,0.16,0.08\}$ & $\{0.02,0,0.03,0.03,0.02,0.02,0.02\}$ \\
5 & $T$ & $\{0.04,0.02,0.31,0.31,0.16,0.08,0.08$ & & $\{0.01,0,0,0.01,0,0,0.02\}$ \\
6 & $I$ & $\{0.02,0.31,0.31,0.16,0.08,0.08,0.04)$ & $\{0,0,0,0,0,0,0,0\}$
\end{tabular}

$D$ water table depth, $R$ recharge rate, $A$ aquifer media, $S$ soil media, $T$ topography (slope), $I$ impact of vadose zone, $C$ hydraulic conductivity, $W_{k}$ criterion map weight, $a_{i k}$ standardized criterion values

Table 4 The determined ordered weights' factor for the considered PPCFs' parameters based on the selected linguistic quantifiers (Modified after Nadi and Delavar 2011)

\begin{tabular}{llllllll}
\hline Decision strategy & \multicolumn{7}{l}{ Order weights $(n=7)$} \\
\cline { 2 - 8 } & $V_{i k D}$ & $V_{i k R}$ & $V_{i k A}$ & $V_{i k S}$ & $V_{i k T}$ & $V_{i k I}$ & $V_{i k C}$ \\
\hline At least one (OR operator) & 1.00 & 0.00 & 0.00 & 0.00 & 0.00 & 0.00 & 0.00 \\
Most & 0.03 & 0.08 & 0.11 & 0.14 & 0.17 & 0.20 & 0.25 \\
Almost & 0.00 & 0.00 & 0.01 & 0.04 & 0.10 & 0.21 & 0.63 \\
Half (mean operator) & 0.14 & 0.14 & 0.14 & 0.14 & 0.14 & 0.14 & 0.14 \\
A few & 0.34 & 0.16 & 0.13 & 0.11 & 0.10 & 0.09 & 0.08 \\
All (AND operator) & 0.00 & 0.00 & 0.00 & 0.00 & 0.00 & 0.00 & 1.00 \\
\hline
\end{tabular}

$D$ water table depth, $R$ recharge rate, $A$ aquifer media, $S$ soil media, $T$ topography (slope), $I$ impact of vadose zone, $C$ hydraulic conductivity, $V_{i k}$ at each ordered criterion observed locations from 0 to 84.45. This resulting index is a relative measure of vulnerability to contamination in the area. By interpretation, the areas with a higher index values are more compared with those with a lower index values.

\section{The modeling of groundwater vulnerability map using the DRASTIC index (DI) results}

The DI values obtained for each observation location grid center in Table 5 above were plotted using the template model (Fig. 4). The gain continuous values of the obtained DI values were interpolated in GIS environment using kriging technique. Adopting the quantile classification technique according to Rahmati et al.(2016) and Naghibi et al. (2014), the study area was classified into five classes of vulnerable zones where NV (5.67-36.88), VLV (36.88-51.70), LV (51.70-61.28), MV (61.28-70.55) and HV (70.55-84.45). Using these possible groundwater vulnerable classifications, the groundwater vulnerability to pollution index (GVPI) map based on DI modeling results was produced (Fig. 5). Furthermore, the corresponding areal coverage and percentage in each predicted groundwater vulnerable potential zones category were evaluated. The estimated areal extent established that about $85.89 \mathrm{~km}^{2}(3 \%), 343.56 \mathrm{~km}^{2}(12 \%)$ and $1059.31 \mathrm{~km}^{2}(37 \%)$ account for the NV, VLV and LV categories whereas both the MV and HV categories have area coverage of $801.64 \mathrm{~km}^{2}(37 \%)$ and $572.6 \mathrm{~km}^{2}(20 \%)$, respectively (see Fig. 5).

\section{The OWA-DRASTIC index technique application results}

The applied OWA-DRASTIC index model established algorithm (Eq. 2) in the area vulnerability assessment produced by the results presented in Tables. Such ODIM application results are detailed in Tables 3, 4, 6 and 7. In 
Table 5 The estimated DRASTIC index (DI) values results

\begin{tabular}{|c|c|c|c|c|c|c|c|c|c|c|c|c|c|c|c|c|c|}
\hline \multirow[t]{2}{*}{ Loc Nos. } & \multicolumn{2}{|c|}{ Obs Center's coordinates } & \multicolumn{2}{|c|}{$D(W=5)$} & \multicolumn{2}{|c|}{$R(W=4)$} & \multicolumn{2}{|c|}{$A(W=3)$} & \multicolumn{2}{|c|}{$S(W=2)$} & \multicolumn{2}{|c|}{$T(W=1)$} & \multicolumn{2}{|c|}{$I(W=5)$} & \multicolumn{2}{|c|}{$C(W=3)$} & \multirow{2}{*}{$\begin{array}{l}\text { DI } \\
\sum W_{i} * R_{i}\end{array}$} \\
\hline & LONG & LAT & $R$ & $R^{*} W$ & $R$ & $R^{*} W$ & $R$ & $R^{*} W$ & $R$ & $R^{*} W$ & $R$ & $R^{*} W$ & $R$ & $R^{*} W$ & $R$ & $R^{*} W$ & \\
\hline 1 & $733,321.75$ & $468,233.36$ & 0 & 0 & 0 & 0 & 0 & 0 & 0 & 0 & 0 & 0 & 0 & 0 & 0 & 0 & 0 \\
\hline 2 & $743,977.93$ & $468,233.36$ & 0 & 0 & 0 & 0 & 0 & 0 & 0 & 0 & 0 & 0 & 0 & 0 & 0 & 0 & 0 \\
\hline 3 & $754,386.28$ & $468,233.36$ & 3 & 15 & 3 & 12 & 2 & 6 & 3 & 6 & 2 & 2 & 3 & 15 & 1 & 3 & 58.95 \\
\hline 4 & $765,042.46$ & $468,233.36$ & 4 & 20 & 3 & 12 & 5 & 15 & 1 & 2 & 2 & 2 & 1 & 5 & 1 & 3 & 58.8 \\
\hline 5 & $775,450.82$ & $468,233.36$ & 0 & 0 & 0 & 0 & 0 & 0 & 0 & 0 & 0 & 0 & 0 & 0 & 0 & 0 & 0 \\
\hline 6 & 786,107 & $468,233.36$ & 0 & 0 & 0 & 0 & 0 & 0 & 0 & 0 & 0 & 0 & 0 & 0 & 0 & 0 & 0 \\
\hline 7 & $733,321.75$ & $456,833.73$ & 0 & 0 & 0 & 0 & 0 & 0 & 0 & 0 & 0 & 0 & 0 & 0 & 0 & 0 & 0 \\
\hline 8 & $743,977.93$ & $456,833.73$ & 3 & 15 & 4 & 16 & 3 & 9 & 4 & 8 & 1 & 1 & 4 & 20 & 1 & 3 & 71.1 \\
\hline 9 & $754,386.28$ & $456,833.73$ & 4 & 20 & 4 & 16 & 4 & 12 & 4 & 8 & 2 & 2 & 5 & 25 & 1 & 3 & 84.45 \\
\hline 10 & $765,042.46$ & $456,833.73$ & 4 & 20 & 5 & 20 & 1 & 3 & 3 & 6 & 4 & 4 & 5 & 25 & 1 & 3 & 80.25 \\
\hline 11 & $775,450.82$ & $456,833.73$ & 4 & 20 & 4 & 16 & 3 & 9 & 1 & 2 & 2 & 2 & 5 & 25 & 2 & 6 & 78.75 \\
\hline 12 & 786,107 & $456,833.73$ & 0 & 0 & 0 & 0 & 0 & 0 & 0 & 0 & 0 & 0 & 0 & 0 & 0 & 0 & 0 \\
\hline 13 & $733,321.75$ & $445,434.1$ & 3 & 15 & 3 & 12 & 5 & 15 & 5 & 10 & 1 & 1 & 4 & 20 & 1 & 3 & 75.45 \\
\hline 14 & $743,977.93$ & $445,434.1$ & 3 & 15 & 3 & 12 & 4 & 12 & 5 & 10 & 1 & 1 & 4 & 20 & 1 & 3 & 72.3 \\
\hline 15 & $754,386.28$ & $445,434.1$ & 3 & 15 & 3 & 12 & 5 & 15 & 5 & 10 & 1 & 1 & 5 & 25 & 1 & 3 & 80.7 \\
\hline 16 & $765,042.46$ & $445,434.1$ & 4 & 20 & 4 & 16 & 5 & 15 & 4 & 8 & 2 & 2 & 3 & 15 & 1 & 3 & 77.85 \\
\hline 17 & $775,450.82$ & $445,434.1$ & 3 & 15 & 3 & 12 & 3 & 9 & 1 & 2 & 3 & 3 & 5 & 25 & 2 & 6 & 71.7 \\
\hline 18 & 786,107 & $445,434.1$ & 0 & 0 & 0 & 0 & 0 & 0 & 0 & 0 & 0 & 0 & 0 & 0 & 0 & 0 & 0 \\
\hline 19 & $733,321.75$ & $434,034.46$ & 4 & 20 & 1 & 4 & 1 & 3 & 1 & 2 & 1 & 1 & 1 & 5 & 2 & 6 & 41.1 \\
\hline 20 & $743,977.93$ & $434,034.46$ & 4 & 20 & 1 & 4 & 1 & 3 & 1 & 2 & 4 & 4 & 4 & 20 & 1 & 3 & 55.5 \\
\hline 21 & $754,386.28$ & $434,034.46$ & 4 & 20 & 2 & 8 & 4 & 12 & 4 & 8 & 2 & 2 & 5 & 25 & 2 & 6 & 79.35 \\
\hline 22 & $765,042.46$ & $434,034.46$ & 2 & 10 & 1 & 4 & 3 & 9 & 3 & 6 & 4 & 4 & 3 & 15 & 2 & 6 & 53.7 \\
\hline 23 & $775,450.82$ & $434,034.46$ & 1 & 5 & 2 & 8 & 4 & 12 & 3 & 6 & 2 & 2 & 1 & 5 & 3 & 9 & 46.95 \\
\hline 24 & 786,107 & $434,034.46$ & 1 & 5 & 2 & 8 & 4 & 12 & 1 & 2 & 4 & 4 & 1 & 5 & 4 & 12 & 47.7 \\
\hline 25 & $733,321.75$ & $422,882.65$ & 5 & 25 & 1 & 4 & 3 & 9 & 3 & 6 & 4 & 4 & 4 & 20 & 3 & 9 & 76.35 \\
\hline 26 & $743,977.93$ & $422,882.65$ & 4 & 20 & 1 & 4 & 3 & 9 & 3 & 6 & 5 & 5 & 5 & 25 & 2 & 6 & 74.25 \\
\hline 27 & $754,386.28$ & $422,882.65$ & 2 & 10 & 2 & 8 & 3 & 9 & 3 & 6 & 2 & 2 & 5 & 25 & 1 & 3 & 62.4 \\
\hline 28 & $765,042.46$ & $422,882.65$ & 2 & 10 & 1 & 4 & 4 & 12 & 4 & 8 & 1 & 1 & 5 & 25 & 2 & 6 & 65.1 \\
\hline 29 & $775,450.82$ & $422,882.65$ & 1 & 5 & 2 & 8 & 2 & 6 & 4 & 8 & 2 & 2 & 4 & 20 & 4 & 12 & 59.85 \\
\hline 30 & 786,107 & $422,882.65$ & 2 & 10 & 2 & 8 & 4 & 12 & 3 & 6 & 4 & 4 & 1 & 5 & 4 & 12 & 56.1 \\
\hline 31 & $733,321.75$ & $411,235.2$ & 0 & 0 & 0 & 0 & 0 & 0 & 0 & 0 & 0 & 0 & 0 & 0 & 0 & 0 & 0 \\
\hline 32 & $743,977.93$ & $411,235.2$ & 5 & 25 & 2 & 8 & 3 & 9 & 3 & 6 & 5 & 5 & 3 & 15 & 2 & 6 & 73.35 \\
\hline 33 & $754,386.28$ & $411,235.2$ & 5 & 25 & 2 & 8 & 3 & 9 & 4 & 8 & 3 & 3 & 3 & 15 & 4 & 12 & 79.05 \\
\hline 34 & $765,042.46$ & $411,235.2$ & 0 & 0 & 0 & 0 & 0 & 0 & 0 & 0 & 0 & 0 & 0 & 0 & 0 & 0 & 0 \\
\hline 35 & $775,450.82$ & $411,235.2$ & 1 & 5 & 2 & 8 & 1 & 3 & 3 & 6 & 1 & 1 & 1 & 5 & 5 & 15 & 43.35 \\
\hline 36 & 786,107 & $411,235.2$ & 2 & 10 & 2 & 8 & 4 & 12 & 3 & 6 & 2 & 2 & 4 & 20 & 4 & 12 & 68.4 \\
\hline
\end{tabular}

$D$ water table depth, $R$ recharge rate, $A$ aquifer media, $S$ soil media, $T$ topography (slope), $I$ impact of vadose zone, $C$ hydraulic conductivity, $R$ rating, $W$ assigned weight and DI drastic index

Tables 3 and 4, there are two set of weights $\left(Z_{i k}\right.$ and $\left.V_{i k}\right)$ being the major drivers in OWA-DRASTIC index modeling feasibility. With the use of the determined ordered weights factor for each DRASTIC model parameters in Table 4, the OWA-DRASTIC index algorithm was defined for each users decision strategies operators, i.e., OWADRASTIC $_{\mathrm{OR}}$ operator index, OWA-DRASTIC ${ }_{\mathrm{ALMOST}}$ operator index, OWA-DRASTIC ${ }_{\text {AFEW }}$ operator index, OWA-DRASTIC $_{\text {MOST }}$ operator index, OWA-DRASTICMEAN operator and OWA-DRASTIC ${ }_{\text {AND }}$ operator index (see the typical Eq. 2). Table 6 presents the results of the index values at each ith-location determined applying these operators' algorithms. 


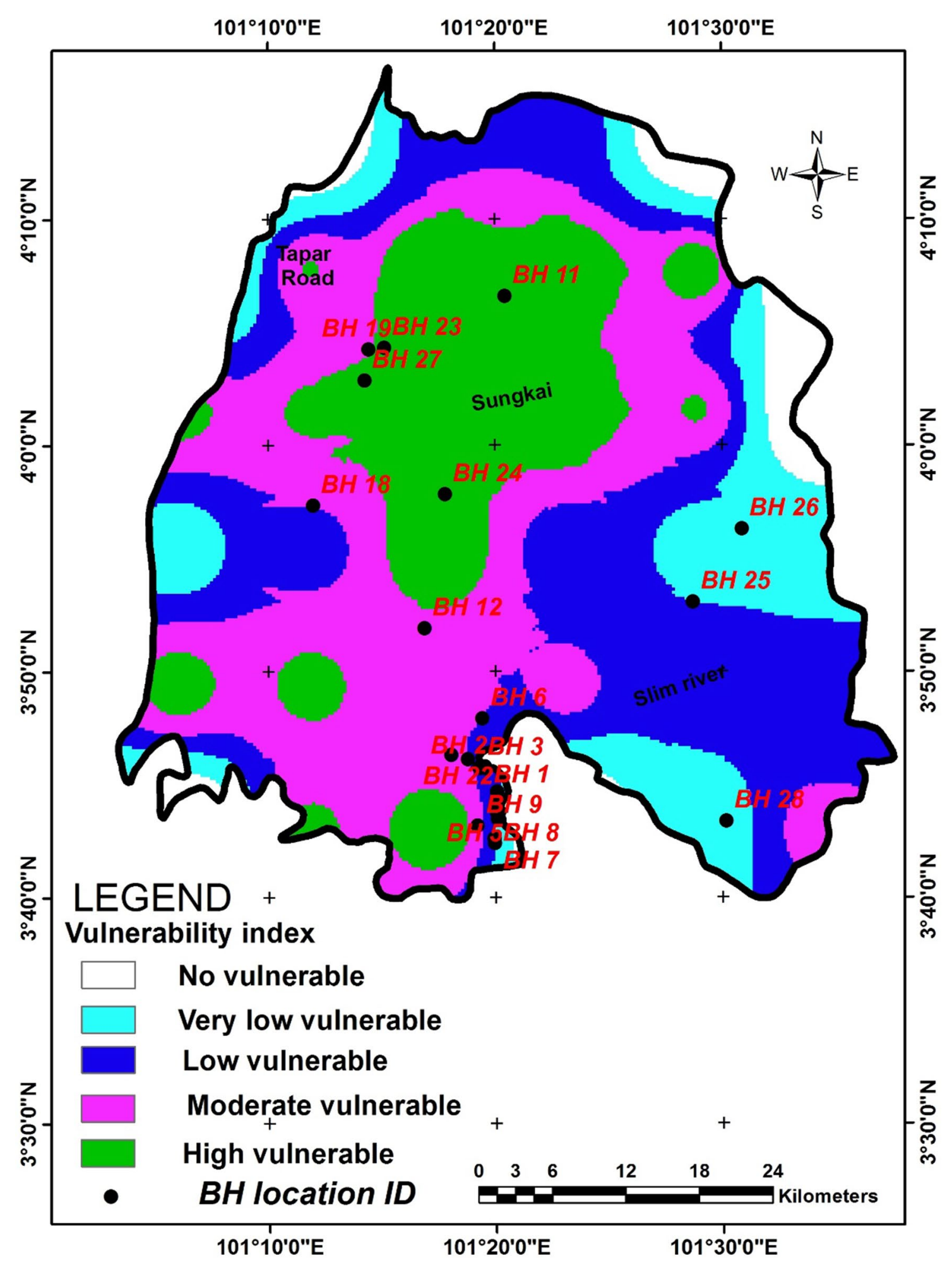

Fig. 5 DRASTIC model groundwater vulnerability to pollution index (GVPI) map 
Table 6 The computed results for the various OWA-DRASTIC operator indexes
Table 7 The OWA-DRASTIC operators' indexes continuous value classified ranges study area

\begin{tabular}{|c|c|c|c|c|c|c|c|c|}
\hline \multirow[t]{2}{*}{ Grid No } & \multicolumn{2}{|c|}{ Grid Center's coordinate } & \multicolumn{6}{|c|}{$\begin{array}{l}\text { OWA-DRASTIC operators indexes for the user's decision } \\
\text { strategies }\end{array}$} \\
\hline & Long & Lat & $A$ & B & $C$ & $D$ & $\mathrm{E}$ & $\mathrm{F}$ \\
\hline 1 & $101^{\circ} 17^{\prime} 26.2^{\prime \prime}$ & $4^{\circ} 13^{\prime} 58.2^{\prime \prime}$ & 0.1550 & 0.0929 & 0.0621 & 0.0051 & 0.0331 & 0.0000 \\
\hline 2 & $101^{\circ} 23^{\prime} 11.6^{\prime \prime}$ & $4^{\circ} 13^{\prime} 57.1^{\prime \prime}$ & 0.2325 & 0.1038 & 0.0568 & 0.0013 & 0.0229 & 0.0000 \\
\hline 3 & $101^{\circ} 11^{\prime} 47.8^{\prime \prime}$ & $4^{\circ} 7^{\prime} 48.1^{\prime \prime}$ & 0.2325 & 0.1275 & 0.0825 & 0.0063 & 0.0433 & 0.0000 \\
\hline 4 & $101^{\circ} 17^{\prime} 25.1^{\prime \prime}$ & $4^{\circ} 7^{\prime} 47.2^{\prime \prime}$ & 0.3100 & 0.1691 & 0.1082 & 0.0082 & 0.0556 & 0.0000 \\
\hline 5 & $101^{\circ} 23^{\prime} 10.5^{\prime \prime}$ & $4^{\circ} 7^{\prime} 46.2^{\prime \prime}$ & 0.3100 & 0.1680 & 0.1054 & 0.0046 & 0.0509 & 0.0000 \\
\hline 6 & 1012847.75 & $4^{\circ} 7^{\prime} 45.13^{\prime \prime}$ & 0.3100 & 0.1680 & 0.1054 & 0.0046 & 0.0509 & 0.0000 \\
\hline 7 & $101^{\circ} 6^{\prime} 1.4^{\prime \prime}$ & $4^{\circ} 1^{\prime} 38.1^{\prime \prime}$ & 0.3100 & 0.1664 & 0.1046 & 0.0075 & 0.0521 & 0.0000 \\
\hline 8 & $101^{\circ} 11^{\prime} 46.7^{\prime \prime}$ & $4^{\circ} 1^{\prime} 37.1^{\prime \prime}$ & 0.2325 & 0.1277 & 0.0839 & 0.0083 & 0.0462 & 0.0000 \\
\hline 9 & $101^{\circ} 17^{\prime} 24.1^{\prime \prime}$ & $4^{\circ} 1^{\prime} 36.2^{\prime \prime}$ & 0.2325 & 0.1255 & 0.0811 & 0.0076 & 0.0434 & 0.0000 \\
\hline 10 & $101^{\circ} 23^{\prime} 9.4^{\prime \prime}$ & $4^{\circ} 1^{\prime} 35.2^{\prime \prime}$ & 0.3100 & 0.1545 & 0.0950 & 0.0083 & 0.0485 & 0.0000 \\
\hline 11 & $101^{\circ} 28^{\prime} 46.6^{\prime \prime}$ & $4^{\circ} 1^{\prime} 34.2^{\prime \prime}$ & 0.2325 & 0.1322 & 0.0889 & 0.0089 & 0.0499 & 0.0000 \\
\hline 12 & $101^{\circ} 6^{\prime} 0 . " 5$ & $3^{\circ} 55^{\prime} 27.0^{\prime \prime}$ & 0.3100 & 0.1491 & 0.0879 & 0.0069 & 0.0415 & 0.0000 \\
\hline 13 & $101^{\circ} 11^{\prime} 45.8^{\prime \prime}$ & $3^{\circ} 55^{\prime} 26.2^{\prime \prime}$ & 0.2325 & 0.0836 & 0.0361 & 0.0000 & 0.0086 & 0.0000 \\
\hline 14 & $101^{\circ} 17^{\prime} 23.0^{\prime \prime}$ & $3^{\circ} 55^{\prime} 25.2^{\prime \prime}$ & 0.2325 & 0.1191 & 0.0686 & 0.0005 & 0.0272 & 0.0000 \\
\hline 15 & $101^{\circ} 23^{\prime} 8.3^{\prime \prime}$ & $3^{\circ} 55^{\prime} 24.3^{\prime \prime}$ & 0.3100 & 0.1610 & 0.0996 & 0.0131 & 0.0505 & 0.0050 \\
\hline 16 & $101^{\circ} 28^{\prime} 45.5^{\prime \prime}$ & $3^{\circ} 55^{\prime} 23.3^{\prime \prime}$ & 0.1550 & 0.0764 & 0.0468 & 0.0066 & 0.0245 & 0.0000 \\
\hline 17 & $101^{\circ} 34^{\prime} 30.7^{\prime \prime}$ & $3^{\circ} 55^{\prime} 22.2^{\prime \prime}$ & 0.0600 & 0.0353 & 0.0243 & 0.0023 & 0.0139 & 0.0000 \\
\hline 18 & $101^{\circ} 5^{\prime} 59.6^{\prime \prime}$ & $3^{\circ} 49^{\prime} 24 .^{\prime \prime}$ & 0.0600 & 0.0353 & 0.0243 & 0.0023 & 0.0139 & 0.0000 \\
\hline 19 & $101^{\circ} 11^{\prime} 44.8^{\prime \prime}$ & $3^{\circ} 49^{\prime} 23.2^{\prime \prime}$ & 0.3100 & 0.1567 & 0.0939 & 0.0076 & 0.0443 & 0.0000 \\
\hline 20 & $101^{\circ} 17^{\prime} 22.1^{\prime \prime}$ & $3^{\circ} 49^{\prime} 22.3^{\prime \prime}$ & 0.3100 & 0.1202 & 0.0586 & 0.0031 & 0.0209 & 0.0000 \\
\hline 21 & $101^{\circ} 23^{\prime} 7.3^{\prime \prime}$ & $3^{\circ} 49^{\prime} 21.4^{\prime \prime}$ & 0.3100 & 0.1313 & 0.0704 & 0.0052 & 0.0299 & 0.0000 \\
\hline 22 & $101^{\circ} 28^{\prime} 44.4^{\prime \prime}$ & $3^{\circ} 49^{\prime} 20.4^{\prime \prime}$ & 0.3100 & 0.1323 & 0.0711 & 0.0040 & 0.0297 & 0.0000 \\
\hline 23 & $101^{\circ} 34^{\prime} 29.6^{\prime \prime}$ & $3^{\circ} 49^{\prime} 19.4^{\prime \prime}$ & 0.2325 & 0.1006 & 0.0554 & 0.0048 & 0.0248 & 0.0000 \\
\hline 24 & $101^{\circ} 11^{\prime} 43.9^{\prime \prime}$ & $3^{\circ} 43^{\prime} 4.2^{\prime \prime}$ & 0.0775 & 0.0520 & 0.0396 & 0.0087 & 0.0267 & 0.0000 \\
\hline 25 & $101^{\circ} 17^{\prime} 21.1^{\prime \prime}$ & $3^{\circ} 43^{\prime} 3.3^{\prime \prime}$ & 0.3100 & 0.1464 & 0.0864 & 0.0212 & 0.0441 & 0.0200 \\
\hline 26 & $101^{\circ} 28^{\prime} 43.3^{\prime \prime}$ & $3^{\circ} 43^{\prime} 1.4^{\prime \prime}$ & 0.3100 & 0.1510 & 0.0921 & 0.0193 & 0.0492 & 0.0100 \\
\hline 27 & $101^{\circ} 34^{\prime} 28.5^{\prime \prime}$ & $3^{\circ} 43^{\prime} 0.5^{\prime \prime}$ & 0.0800 & 0.0365 & 0.0200 & 0.0003 & 0.0078 & 0.0000 \\
\hline
\end{tabular}

$A$ OWA-DRASTIC $_{\mathrm{OR}}, B$ OWA-DRASTIC A FEW $C$ OWA-DRASTIC $_{\text {MEAN }}, D$ OWA-DRASTIC $_{\text {ALMOST }}, E$ OWA-DRASTIC $_{\text {MOST }}, F$ OWA-DRASTIC ${ }_{\mathrm{AND}}$

\begin{tabular}{llllll}
\hline$A$ & $B$ & $C$ & $D$ & $E$ & $F$ \\
\hline $0.0601-0.1169$ & $0.0000-0.0009$ & $0.0200-0.0452$ & $0.0083-0.0332$ & $0.0353-0.0726$ & $0.0000-0.0040$ \\
$0.1169-0.1659$ & $0.0009-0.0033$ & $0.0452-0.0619$ & $0.0332-0.0486$ & $0.0726-0.1004$ & $0.0040-0.0063$ \\
$0.1659-0.2188$ & $0.0033-0.0070$ & $0.0619-0.0767$ & $0.0486-0.0652$ & $0.1004-0.1214$ & $0.0063-0.0093$ \\
$0.2188-0.2678$ & $0.0070-0.0126$ & $0.0767-0.8892$ & $0.0652-0.0835$ & $0.1214-0.1397$ & $0.0093-0.0141$ \\
$0.2678-0.3100$ & $0.0126-0.0200$ & $0.8891-0.1082$ & $0.0835-0.1142$ & $0.1397-0.1691$ & $0.0141-0.0212$ \\
\hline
\end{tabular}

$A$ OWA-DRASTIC $_{\mathrm{OR}}, B$ OWA-DRASTIC AND,$C$ OWA-DRASTIC $_{\mathrm{MEAN}}, D$ OWA-DRASTIC $_{\text {MOST }}, E$ OWADRASTIC $_{\text {AFEW }}, F$ OWA-DRASTIC ALMOST $_{\text {OLT }}$

\section{Pollution potential interpretation of the OWA-DRASTIC model operator indexes analysis}

The computed indexes results based on the selected operator's users decision strategy in Table 6 are the relative measures of vulnerability to contamination characteristics in the area. The interpretation of the resulting operators' indexes values is such that areas with a higher index value are more vulnerable, as compared with those with a lower index. Deducing from the various operators' indexes values, the degree of vulnerability per location in the area varies from one operator index algorithm to another (Table 6). This is because the users' decision strategy characterizing the 
developed OWA-DRASTIC model allows diverse vulnerability assessment performance through flexibility using of varying numbers of pollution potential criteria input in the established vulnerability model (Eq. 2). The records in Table 6 were further processed in GIS environment to demarcate the continuous indexes values into class boundary ranges using the ad hoc classification technique of Rahmati et al. (2016) and Naghibi et al. (2014) to define the vulnerability potential classes in the area. The classified ranges boundary for various strategy decision operators is shown in Table 7. These operators' indexes classified ranges are interpretable for vulnerability assessment in the area. The attribute of these operators' indexes strategies implication in vulnerability assessment varied as discussed in the literature (Gorsevski et al. 2012; Mogaji et al. 2014). The OWA-DRASTIC $_{\mathrm{AND}}$ index operator was chosen over other operators' indexes for its reasons of risk aversion solution advantage (Bell et al. 2007). Besides, Nadi and Delavar (2011) has also established that the performance of AND operator user's decision strategy in his study to be the best among other operator indexes Thus, this OWA-DRASTI$\mathrm{C}_{\mathrm{AND}}$ operator index classification was preferred to be more suitable for developing vulnerability modeling prediction of higher reliability and precision in the study area.

\section{The modeling of groundwater vulnerability map using the OWA-DRASTIC ${ }_{\text {AND }}$ index operator result}

The OWA-DRASTIC ${ }_{\text {AND }}$ index values obtained for each observation location grid center in Table 7 above were plotted using the template model (Fig. 4). The gain continuous values of the obtained OWA-DRASTIC AND $_{\text {index }}$ values were interpolated in GIS environment using kriging technique. The quantile classification technique was also used to classify the area into five classes of vulnerable zones where NV (0.0000-0.0009), VLV (0.0009-0.0033), LV (0.0033-0.0070), MV (0.0007-0.0126) and HV (0.0126-0.0200) (see Table 7). Using these possible groundwater vulnerable classifications, the groundwater vulnerability to pollution index (GVPI) map based on OWADRASTIC $_{\text {AND }}$ index results was produced (Fig. 6). The corresponding areal coverage and percentage in each predicted groundwater potential zones category were evaluated where about $2095 \mathrm{~km}^{2}(73 \%), 479 \mathrm{~km}^{2}(17 \%)$ and $149 \mathrm{~km}^{2}(5 \%)$ account for the NV, VLV and LV categories whereas both the MV and HV categories have area coverage of $117 \mathrm{~km}^{2}$ (4\%) and $23 \mathrm{~km}^{2}(1 \%)$, respectively (Fig. 6).

\section{Model validation}

For the purpose of establishing the reliability and precision of the spatial predictive model indexes in environmental decision-making studies, the above task is very crucial. Thus, in line with Manap et al. (2011), the produced groundwater vulnerability prediction maps (Figs. 5, 6) were appraised with validation analysis. The most widely used validation technique of assessing the reliability of vulnerability index is via determining correlation between the nitrate concentration and the spatial-predicted vulnerability index values (Antonakos and Lambrakis 2007; Nobre et al. 2007; Chen et al. 2013; Pradhan et al. 2013; Thirumalaivasan et al. 2003; Panagopoulos et al. 2006; Javadi et al. 2011a, b; Singh et al. 2015). This is because, the DRASTIC model often assumes that the contaminant has the mobility of water particularly the nitrate which is a highly mobile contaminant that originates from a variety of point and nonpoint sources such as nitrogenous fertilizers that usually increase nitrate contamination of groundwater resources especially in an extensive cultivated agricultural site (Qi and Gurdak 2006). However, it is not only nitrate compound that degrades groundwater quality, other physio-chemical parameters and heavy metals elements that derived their sources from other environmental activities including anthropogenic activities and weathering of source rocks and recharge from water bodies are also culprit to groundwater contamination (Singh et al. 2015; De Vries and Simmer 2002; Anirban et al. 2016). The consumption of such other chemical elements that are readily soluble in water is inimical to the body system. As such, the approach according to Kalinski et al. (1994), McLay et al. (2001) and Alam et al. (2012) where chemical contaminant parameters and vulnerability index relationship is analyzed for spatial model validation is considered in this study. Though, despite the fact that the study area is vastly covered with agricultural lands, presently there is no report of groundwater contamination problems in the area. Thus, this study aimed to assess impending contamination to be model from estimated vulnerability index in the area. Therefore, some physio-chemical parameters and heavy metals element concentrations information were extracted from the groundwater quality analysis data obtained from the drilled boreholes in the area (see Figs. 5, 6). The determined physio-chemical parameters and heavy metals that were assumed to be completely soluble in water include $\mathrm{pH}$, TDS, nitrate $\left(\mathrm{NO}_{3}\right)$, sulfate $\left(\mathrm{SO}_{4}\right)$, calcium $(\mathrm{Ca})$, iron $(\mathrm{Fe})$, zinc $(\mathrm{Zn})$ and manganese $(\mathrm{Mn})$. With this groundwater quality analyzed records, two validation schemes were used to assess the efficiency of the applied DRASTIC index model (DIM) and OWA-DRASTIC index model (ODIM) vulnerability assessment techniques: these schemes include: (a) water quality status-vulnerability zones relationship scheme and (b) pollution causative element-vulnerability index values correlation scheme. This concept is in agreement with Anirban et al. (2016) who buttressed the use of multiple water quality parameters in evaluating prospective vulnerability maps better than the past studies that have focused on 


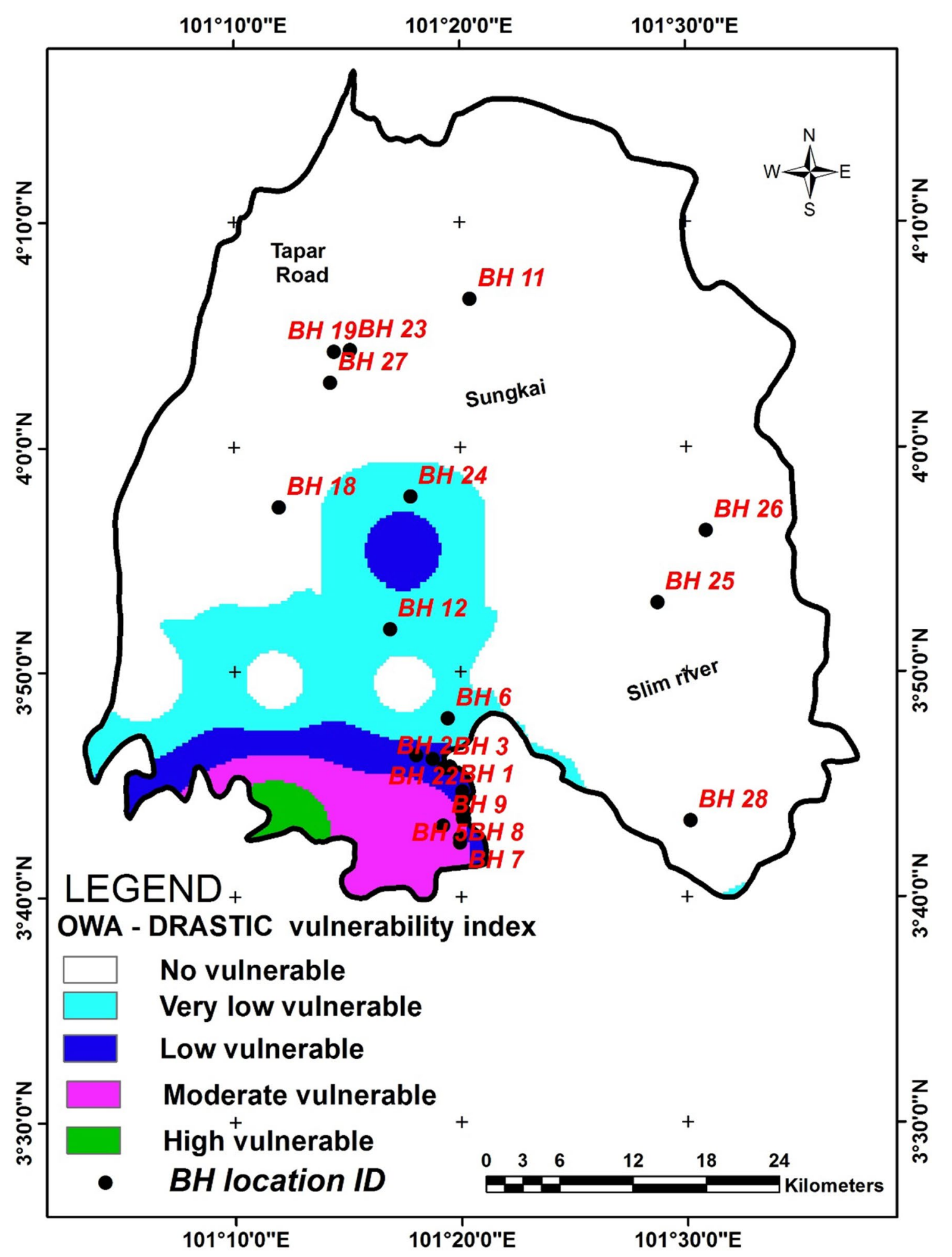

Fig. 6 OWA-DRASTIC model groundwater vulnerability to pollution index map 
single-water quality parameter means of validating DRASTIC index.

\section{Water quality status-vulnerability zones relationship scheme}

In order to establish this relationship scheme, the analyzed chemical parameters and elements concentrations were compared with the WHO (World Health Organization) and Food and Agriculture Organization (FAO) standards to assess the water quality status of the samples obtained from the groundwater bore wells. Enforcing these standards, for each determined chemical parameters whose concentration $(\mathrm{mg} / \mathrm{l})$ is within the permissible limit $Y$ is indicated whereas where we have the measured concentration exceeding or below the permissible limit, $X$ is indicated. Consequently, the water quality in the area was classified into good and bad status (see Table 8). Further, the concept of ascribing protected areas and not protected areas to the classes of low vulnerable potential zones and the moderate-high vulnerable potential zones in a regional vulnerability model index map is used to describe good water quality areas and bad water quality areas, respectively, based on the submission of Artiqur Rahman (2008) and Thirumalaivasan et al. (2003). Hence, the predicted vulnerable potential zones of the GVPI maps (Figs. 5, 6) are reclassified thus in Table 9. Considering the information in Tables 8, 9 and Figs. 5, 6, the physio-chemical parameters and heavy metal elements concentration measurements were analyzed for the DIM and ODIM methods validation using the water quality status-vulnerability zones relationship approach. Tables 10 and 11 present the vulnerability index prediction validation results for the DIM and ODIM methods. According to Tables 10 and 11, the DIM and ODIM methods show 64.29 and $85.71 \%$ prediction accuracies result, respectively. It thus implies that about 24 and 18 borehole wells' water quality status information correctly coincided with the predicted vulnerable index zones of the models, respectively, whereas only 4 and 10 borehole wells were not coincided. The OWA-DRASTIC index model (ODIM)-based GVPI map represents better scenario of vulnerability as compared to conventional DRASTIC index model (DIM)-based GVPI map in view of their validation with the field observations of groundwater quality.
Table 9 The possible vulnerability zones potential classifications (after Artiqur Rahman 2008 and Thirumalaivasan et al. 2003)

\begin{tabular}{lll}
\hline Vulnerability zones category & $\begin{array}{l}\text { Vulnerability poten- } \\
\text { tial remark }\end{array}$ & Symbol \\
\hline NV,VLV and LV & Protected & P \\
MV and HV & Not protected & NP \\
\hline
\end{tabular}

\section{Pollution causative elements-vulnerability index values correlation scheme}

In accordance with Pearson (1900) and Snedecor and Cochran (1980), correlation is a method for scrutinizing the connection between two measurable and continuous variables. This second validation scheme is a quantitative correlation approach. From the analyzed groundwater quality data, the areas water quality is relatively in good status. However, among the analyzed the physio-chemical parameters and heavy metal elements for water quality status in the area, the concentration of $\mathrm{pH}$ and manganese chemical elements revealed more evidence of groundwater contamination as indicated by $X$ in columns (4) and (17) of Tables 10 and 11 . With the $\mathrm{pH}$ readings in column (4), the tested water samples in the area are acidic. In accordance with Akinbile and Mohd (2011), the area underground water contains the presence of metals, particularly toxic metals like manganese. Thus, these pollution causative elements ( $\mathrm{pH}$ and $\mathrm{Mn}$ ) were also considered as correlation indices to validate the DIM and ODIM vulnerability techniques. Adopting the similar method employed in the studies of Pradhan et al. (2013) and Singh et al. (2015), the $\mathrm{pH}$ and manganese concentrations were used to develop correlations with the values of both DIM and ODIM techniques. Solving the GIS software with the groundwater bore well locations depicted in Figs. 5 and 6 , the identify tool was used to extract the values for the DIM and ODIM vulnerability index. The extracted vulnerability index values were correlated with their corresponding $\mathrm{pH}$ and manganese $(\mathrm{Mn})$ concentrations values in a plot profile. Figures 7 and 8 present the plots of 28 correlated data pairs. According to the plots, the observed Pearson's correlation coefficient $R$ for the quantitative relationship between the DIM and ODIM and manganese concentration is 63 and 85\%, respectively (Fig. 7). Similarly, the observed
Table 8 Groundwater quality evaluation criteria based on FAO and WHO standards (after FAO 1995 and WHO 2004)

\begin{tabular}{|c|c|c|c|c|c|c|c|c|c|}
\hline \multirow[t]{2}{*}{ Standards } & \multicolumn{5}{|c|}{ Physio-chemical Parameters } & \multicolumn{2}{|c|}{ Heavy metals } & \multicolumn{2}{|c|}{$\begin{array}{l}\text { Water quality } \\
\text { remark }\end{array}$} \\
\hline & $\mathrm{pH}$ & TDS & $\mathrm{NO}_{3}$ & $\mathrm{Ca}$ & $\mathrm{SO}_{4}$ & $\mathrm{Fe}$ & $\mathrm{Mn}$ & Good & $\mathrm{Bac}$ \\
\hline WHO & $6.5-8.5$ & 500 & 50 & 75 & 20 & $0.5-50$ & 0.1 & Y & $X$ \\
\hline FAO & $6.5-8.5$ & 2000 & 10 & 20 & 20 & - & - & & \\
\hline
\end{tabular}

$Y$ good water quality, $X$ bad water quality 


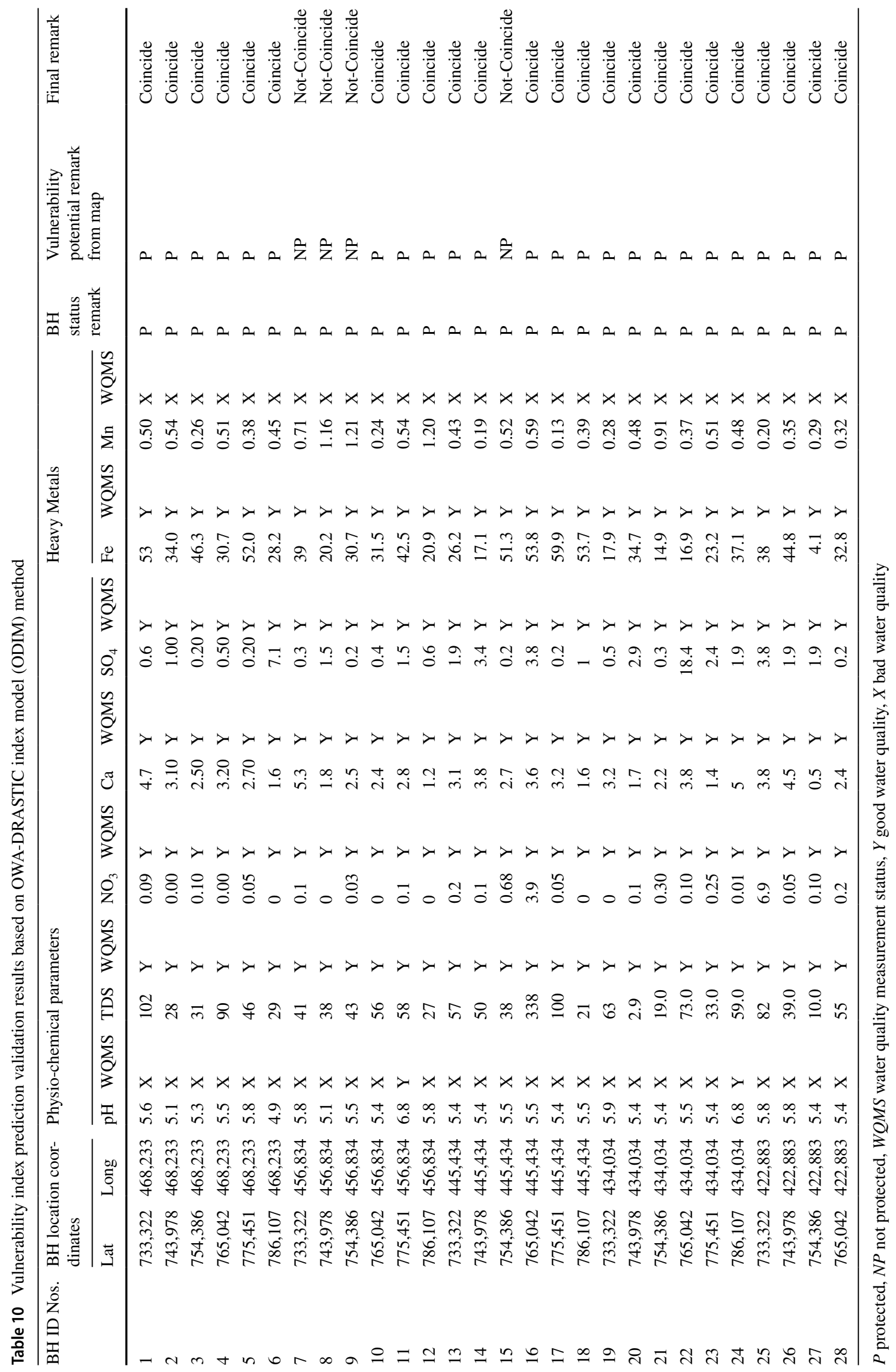




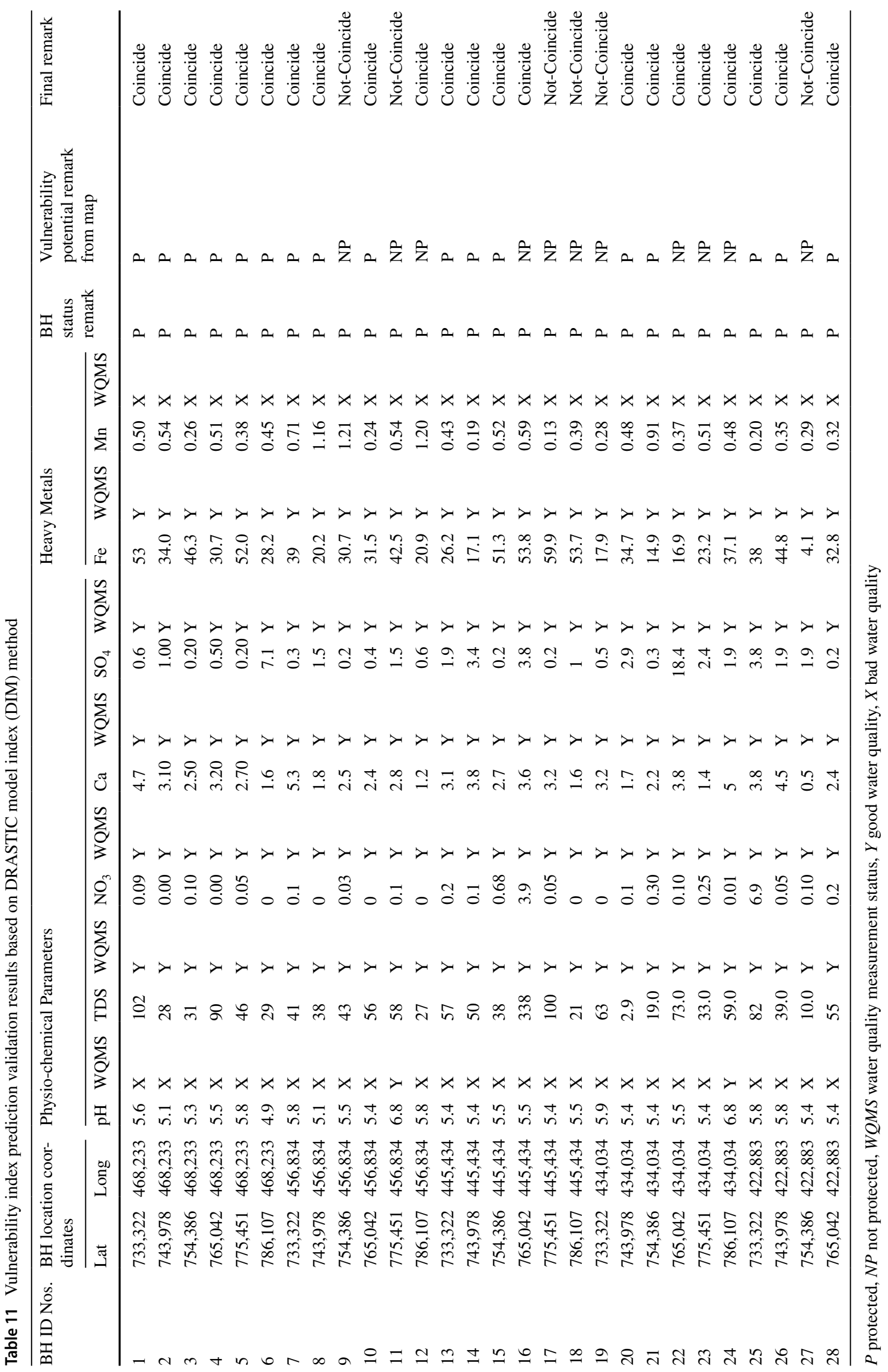


Fig. 7 a Plot between DRASTIC index model (DIM) and manganese concentration $(\mathrm{mg} / \mathrm{l})$. b Plot between OWA-DRASTIC index model (ODIM) and manganese concentration $(\mathrm{mg} / \mathrm{l})$
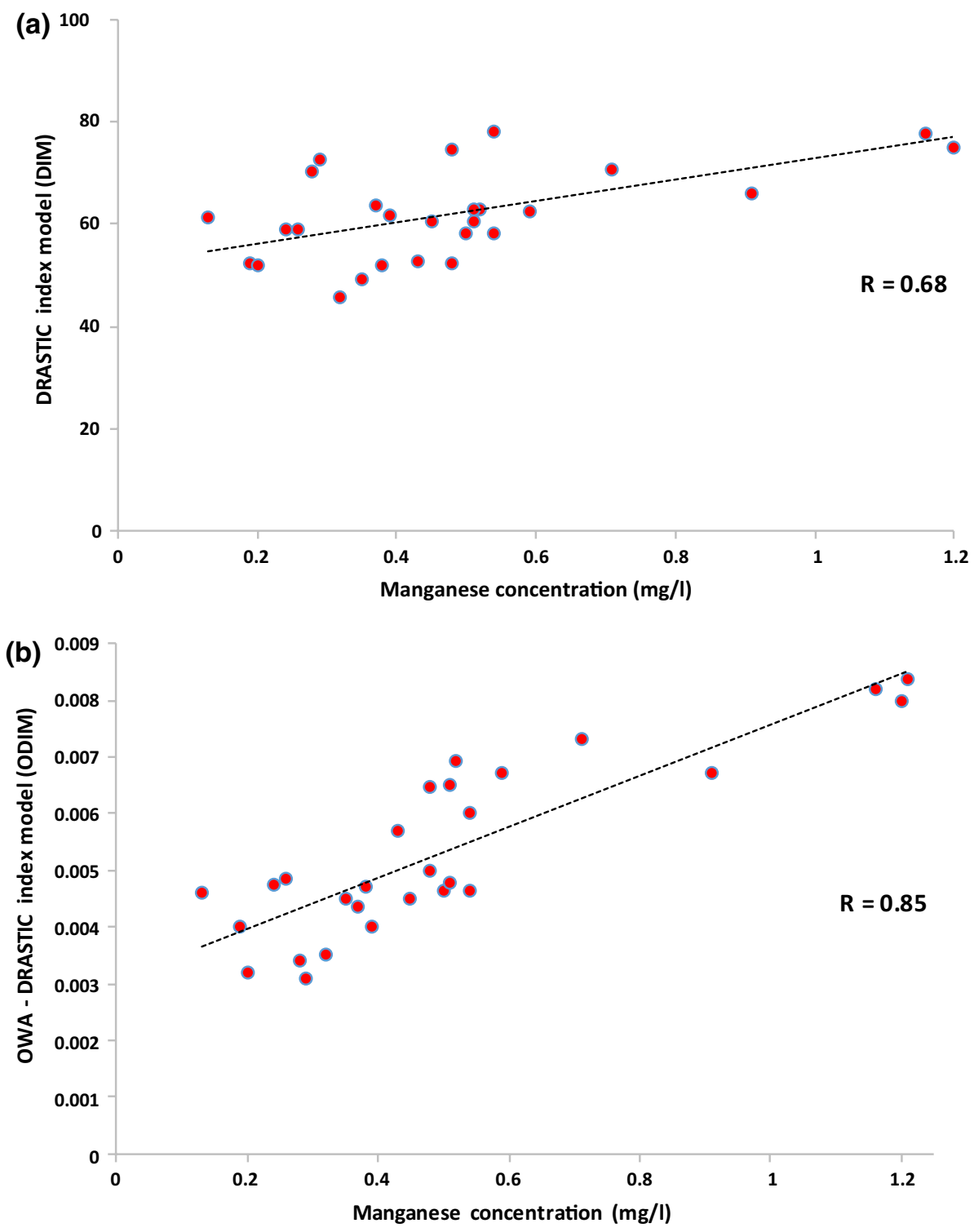

Pearson's correlation coefficient ' $R$ ' for the quantitative relationship between the DIM and ODIM and pH is 68 and $83 \%$, respectively (Fig. 8). The resulting line of fit which shows positive correlation between the DIM and ODIM and both $\mathrm{Mn}$ and $\mathrm{pH}$ concentration further validate these vulnerability modeling techniques in the area.

\section{Model performance and comparison between DIM and ODIM vulnerability techniques}

The performance evaluation's schemes for the DIM and ODIM vulnerability methods have earlier been discussed. The evaluation was with the view of establishing the similarities and the differences between the methods reference to their significance in groundwater vulnerability assessment. Tables 10 and 11 show performance evaluation results for the methods based on water quality status-vulnerability zones relationship scheme. Quantitatively, it can be seen that both investigated methods in the area showed reasonably very good accuracy in spatial prediction of groundwater vulnerability based on the attained prediction accuracies. However, the ODIM method has better percentage accuracy $(>21.42 \%)$ than that of the DIM method. Figures 7 and 8 show the correlation scheme evaluation results. It was found that the correlation between the ODIM and manganese concentration was higher $(0.85)$ in comparison with that of the DIM and observed manganese concentration (0.63). Similarly, the correlation between ODIM and $\mathrm{pH}$ concentration was higher (0.83) in comparison with that of the DIM and observed $\mathrm{pH}$ concentration (0.68). But then, the observed similarity is such that the highest concentrations of both $\mathrm{Mn}$ and $\mathrm{pH}$ correlated well with the highest OWA-DRASTIC index values and DRASTIC index values. With these 
Fig. 8 a Plot between DRASTIC index model (DIM) and $\mathrm{pH}$ concentration $(\mathrm{mg} / \mathrm{l})$. b Plot between OWA-DRASTIC index model (ODIM) and $\mathrm{pH}$ concentration $(\mathrm{mg} / \mathrm{l})$
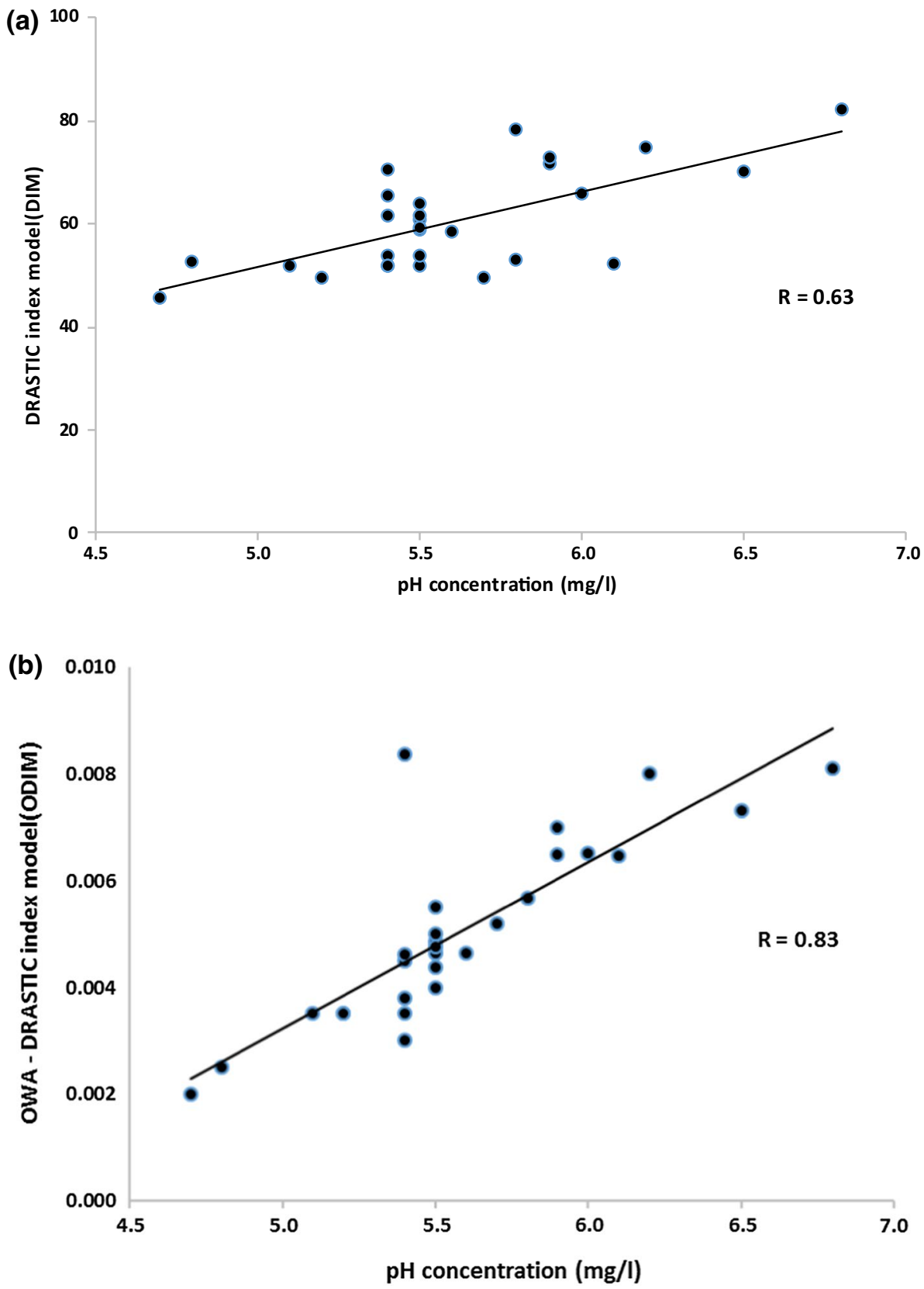

correlation results, the efficiencies of the models (DIM and ODIM) in groundwater vulnerability assessment are further validated. In addition, the percentage computation of the total area under different vulnerability class determined from both ODIM and DIM-based GVPI model maps is as graphically represented in Fig. 9. The results reveal that more than $50 \%$ of the area are under the low vulnerable zones. Such areas are relatively protected for their high resistance to pollution infiltration to groundwater containing medium (the aquifer) (Atiqur Rahman 2008). This finding is in agreement with reason why there has been no challenges of groundwater contamination problems in the study area. Corroboratively, the overlaying analysis of the produced GVPI maps (Figs. 5, 6) and the PPCFs' thematic layers (Fig. 3) which established the possibility of the presence of clayey confining unit (aquifer layers overlain by low permeable materials) and poorly drained soils in the study area could had limited the amount of agricultural chemicals to reach the aquifer. The interpreted results of the area borehole log data (obtained from the Minerals and Geoscience Department, Malaysia) have as well confirmed the existence of the thick column of clayey confining unit overlying the aquifer layer in the area. Since, the rate of pollutant infiltration is largely a function of pollutant residence time in a place, the undulating and steep natures of this area topography/sloping characteristics practically 
Fig. 9 Percentage of vulnerable zones distribution between DIM and ODIM approaches

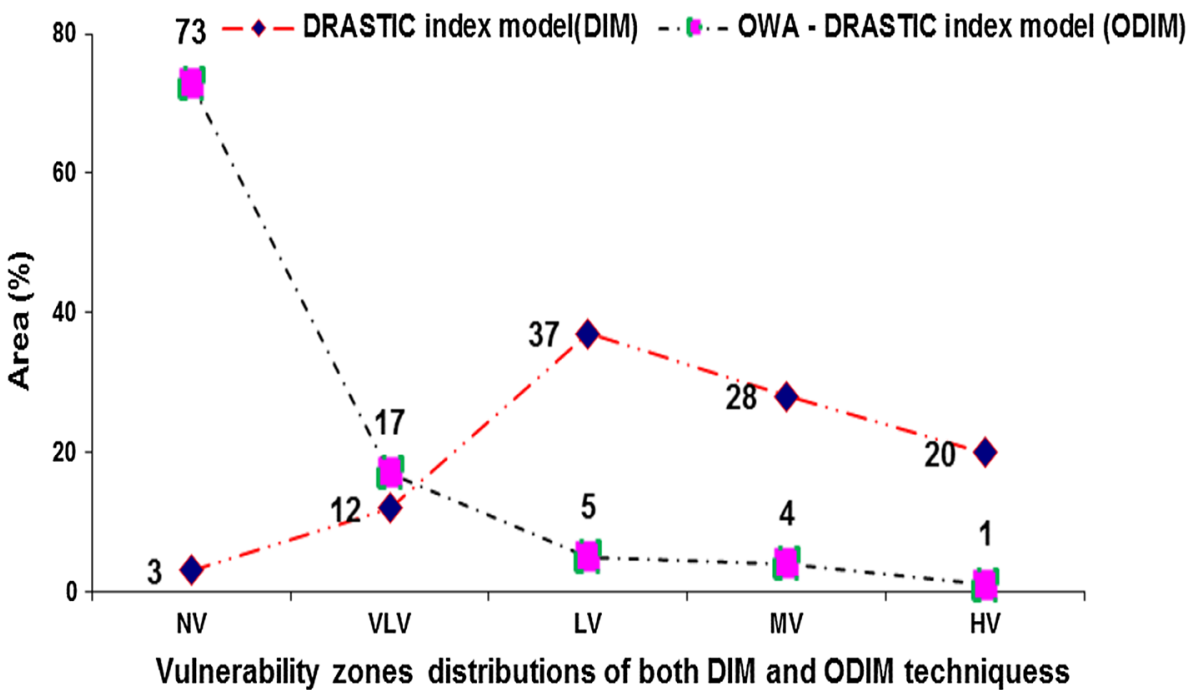

reduced the infiltrating rate of pollutants or contaminants in the subsurface through the high rate of runoff in the area. Thus, the prediction accuracy of both ODIM and DIM vulnerability techniques is quite supported but with the ODIM method having higher efficiency.

\section{Conclusion}

The main conclusions drawn from this study were as follows: (1) The two used vulnerability modeling approaches for aquifer vulnerability mapping vis-à-vis the quality preservation of the groundwater resources have very good capability for predicting potential vulnerable zones with a model accuracy of 63 and $85 \%$ from the Mn concentrations 'correlation factor between the DRASTIC index and the OWA-DRASTIC index predicted values, respectively. Similarly, the accuracy of the $\mathrm{pH}$ concentrations 'correlation factor between the DRASTIC index and the OWA-DRASTIC index predicted values are 68 and $83 \%$, respectively. (2) Based on the FAO and WHO standards, the accuracy of both the DIM-based GVPI map and the ODIM-based GVPI map was established to be 64.29 and $85.71 \%$, respectively. (3) The obtained DIM and ODIM values are classified into five classes: no vulnerable (NV), very low, vulnerable (VLV), low vulnerable (LV), moderate vulnerable (MV) and high vulnerable (HV). (4) The large extent of low potential vulnerable classes $(52 \%$ for DRASTIC index model and $95 \%$ for OWA-DRASTIC index model) implies that the aquifer systems in the study area are highly protected from contamination. (5) The OWA-DRASTIC index method is a more efficient technique to demarcate potential vulnerable zones than DRASTIC index in the area. (6) The groundwater vulnerability to pollution index maps produced by this study can provide valuable information for hydrogeologist, planners and decision makers to put suitable plans for managing groundwater in the study area. The method can be replicated in other areas with similar hydrogeological settings.

Acknowledgements The author is grateful to Universiti Sains Malaysia (USM) for providing 1-year post-doctoral fellowship Dr. Kehinde Anthony Mogaji (USM0214/16). Also special appreciation goes to my University back in Nigeria [Federal University of Technology Akure (FUTA)] for granting me study leave to utilize the fellowship for research study.

Open Access This article is distributed under the terms of the Creative Commons Attribution 4.0 International License (http://creativeco mmons.org/licenses/by/4.0/), which permits unrestricted use, distribution, and reproduction in any medium, provided you give appropriate credit to the original author(s) and the source, provide a link to the Creative Commons license, and indicate if changes were made.

\section{References}

Adiat KAN, Nawawi MNM, Abdullah K (2012) Assessing the accuracy of GIS-based elementary multi criteria decision analysis as a spatial prediction tool- a case of predicting potential zones of sustainable groundwater resources. J Hydrol 440:75-89. https ://doi.org/10.1016/j.jhydrol.2012.03.028

Akinbile CO, Mohd SY (2011) Environmental impact of leachate pollution on groundwater supplies in Akure, Nigeria. Int J Environ Sci Dev 2(1):81

Alam F, Umar R, Ahmad S, Dar AF (2012) Anew model (DRASTICLU) for evaluating groundwater vulnerability in parts of central ganga plain, India. Arab J Geosci 7:927-937

Al-Abadi AM, Pourghasemi HR, Shahid S, Hussain BG (2017) Spatial mapping of groundwater potential using entropy weighted linear aggregate novel approach and GIS. Arab J Sci Eng 42:1185-1199. https://doi.org/10.1007/s13369-016-2374-1

Aller L, Bennett T, Lehr JH, Pretty RJ, Hacket G (1987) DRASTIC: a standardized system for evaluating ground water pollution potential using hydrogeologic settings.US Environmental Protection Agency, Ada, Oklahoma (EPA-600/2-87-035)

Al-Saud M (2010) Mapping potential areas for groundwater storage in Wadi Aurnah Basin, western Arabian Peninsula, using 
remote sensing and geographic information system techniques. Hydrogeol J 18:1481-1495

Anirban D, Satiprasad S, Amlanjyoti K, Chakraborty D (2016) Index-based groundwater vulnerability mapping using quantitative parameters. Environ Earth Sci 75:522. https://doi. org/10.1007/s12665-016-5395-x

Antonakos AK, Lambrakis NJ (2007) Development and testing of three hybrid methods for the assessment of aquifer vulnerability to nitrates, based on the drastic model, an example from NE Korinthia, Greece. J Hydrol 333:288-304. https://doi. org/10.1016/j.jhydrol.2006.08.014

Bell N, Schuurman N, Hayes MV (2007) Using GIS-based methods of multicriteria analysis to construct socio-economic deprivation indices. Int J Health Geogr 6:17. https://doi. org/10.1186/1476-072X-6-17

Biswajeet AN, Pradhan MD (2104) Groundwater vulnerability assessment using an improved DRASTIC method in GIS. Resour Conserv Recycl 86:74-86

Boris RA, Xavier FG, Sánchez JÁ (2016) Assessment of groundwater vulnerability to nitrates from agricultural sources using a GIS-compatible logic multicriteria model. J Environ Manage 171:70-80

Chen Y, Khan S, Paydar Z (2009) To retire or expand? A fuzzy GISbased spatial multi-criteria evaluation framework for irrigated agriculture. Irrig Drain 59(2):174-188

Chen SK, Jang CS, Peng YH (2013) Developing a probability-based model of aquifer vulnerability in an agricultural region. J Hydrol. https://doi.org/10.1016/j.jhydrol.2013.02.019

Ckakraborty S (2007) Assessing aquifer vulnerability to arsenic pollution using DRASTIC and GIS of North Bengal Plain: a case study of English Bazar Block, Malda District, West Bengal, India, vol 7(1). Springer, Berlin

Daly D, Drew D (1999) Irish methodologies for karst aquifer protection. In: Beek B (ed) Hydrogeology and engineering geology of sinkholes and karst. Balkema, Rotterdam, pp 267-327

De Vries JJ, Simmer I (2002) Groundwater recharge: an overview of processes and challenge. Hydrogeol J 10:5-17. https://doi. org/10.1007/s10040-001-0171-7

Dixon B (2005) Groundwater vulnerability mapping: a GIS and fuzzyrule based integrated tool. Appl Geogr 25:327-347

Doumouya I, Dibi B, Kouame IK, Saley B, Jourda JP, Savane I, Biemi J (2012) Modelling of favourable zones for the establishment of water points by geographical information system (GIS) and multi-criteria analysis (MCA) in the Abiosso area (south-east of Cote d'Ivoire). Environ Earth Sci. https://doi.org/10.1007/s1266 5-012-1622-2

Eastman RJ, Jiang H (1996) Fuzzy measures in multi-criteria evaluation. In: Proceedings of the second international symposium of spatially accuracy assessment in natural resources and environmental studies, May 23, 1996, pp 527-534

Ettazarini S, El Mahmouhi N (2004) Vulnerability mapping of the Turonian limestone aquifer in the Phosphates Plateau (Morocco). Environ Geol 46:113-117. https://doi.org/10.1007/s0025 4-004-1022-3

Falah F, Samira Ghorbani N, Omid R, Daneshfar M, Hossein Z (2016) Applicability of generalised additive model in groundwater potential modelling and comparision its performance by bivariate statistical methods. Geocarto Int. https://doi.org/10.1080/10106 049.2016.1188166

FAO (1995) Food and Agriculture Organization (FAO). Environmental impact assessment of irrigation and drainage projects. FAO, Rome

Feizizadeh B, Blaschke T, Nazmfar H (2012) GIS-based ordered weighted averaging and Dempster-Shafer methods for landslide susceptibility mapping in the Urmia Lake Basin, Iran. Int J Digit Earth. https://doi.org/10.1080/17538947.2012.749950
Foster SSD (1987) Fundamental concepts in aquifer vulnerability, pollution risk and protection strategy. Proc Inf TNO Comm Hydrol Res 38:36-86

Fritch TG, McKnight CL, Yelderman JC, Arnold JG (2000) An aquifer vulnerability assessment of the Paluxy aquifer, Central Texas, USA, using GIS and a modified DRASTIC approach. Environ Manage 25:337-345

Gorsevski PV, Donevska KR, Mitrovski CD, Frizado JP (2012) Integrating multi-criteria evaluation techniques with geographic information systems for landfill site selection: a case study using ordered weighted average. Waste Manag 32:287-296. https://doi. org/10.1016/j.wasman.2011.09.023

Huan H, Wang J, Teng Y (2012) Assessment and validation of groundwater vulnerability to nitrate based on a modified DRASTIC model: a case study in Jilin City of northeast China. Sci Total Environ. https://doi.org/10.1016/j.scitotenv.2012.08.037 (article online first available)

Issoufou OP, Defourny MV (2016) Mapping the groundwater vulnerability for pollution at the pan African scale. Sci Total Environ 544:939-953

Javadi S, Kavehkar N, Mousavizadeh MH, Mohammadi K (2011a) Modification of DRASTIC model to map groundwater vulnerability to pollution using nitrate measurements in agricultural areas. J Agric Sci Technol 13(2):239-249

Javadi S, Kavehkar N, Mohammadi K, Khodadi A, Kahawita K (2011b) Calibration DRASTIC using field measurements, sensitivity analysis and statistical method to assess groundwater vulnerability. Water Int 36(6):719-732

Jessica EL, Sonia T (2009) Groundwater vulnerability assessments and integrated water resource management. Streamline Watershed Bull 13(1):18-29

Kalinski RJ, Kelly WE, Bogardi I, Ehrman RL, Yamamoto PO (1994) Correlation between DRASTIC vulnerabilities and incidents of VOC contamination of municipal wells in Nebraska. Ground Water 32(1):31-34

Kumar P, Baban KSB, Sanjit KD, Praveen KT, Ghanshyam C (2017) Index-based groundwater vulnerability mapping models using hydrogeological settings: a critical evaluation. Environ Impact Assess Rev 51:38-49

Malczewski J (1999) GIS and multicriteria decision analysis. Wiley, New York

Malczewski J (2006a) Ordered weighted averaging with fuzzy quantifiers: GIS-based multi-criteria evaluation for land-use suitability analysis. Int J Appl Earth Obs Geoinf 8(4):270-277

Malczewski J (2006b) Integrating multi-criteria analysis and geographic information systems: the ordered weighted averaging (OWA) approach. Int J Environ Technol Manage 6(1):7-19

Manap MA, Sulaiman WNA, Ramli MF, Pradhan B, Surip N (2011) A knowledge-driven GIS modelling technique for groundwater potential mapping at the Upper Langat Basin, Malaysia. Arab J Geosci 6(5):1621-1637. https://doi.org/10.1007/s1251 7-011-0469-2

McLay CDA, Dragden R, Sparling G, Selvarajah N (2001) Predicting groundwater nitrate concentrations in a region of mixed agricultural land use: a comparison of three approaches. Environ Pollut 115:191-204

Mimi ZA, Mahmoud N, Madi MA (2012) Modified DRASTIC assessment for intrinsic vulnerability mapping of karst aquifers: a case study. Environ Earth Sci 66(2):447-456

Mogaji KA (2017) Development of AHPDST vulnerability indexing model for groundwater vulnerability assessment using hydrogeophysical derived parameters and GIS application. Pure appl Geophys 2017(174):1787-1813. https://doi.org/10.1007/s0002 4-017-1499-9

Mogaji KA, Lim HS (2018) Application of Dempster-Shafer theory of evidence model to geoelectric and hydraulic parameters for

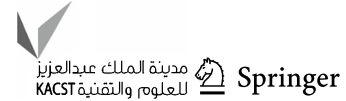


groundwater potential zonation. NRIAG J Astron Geophys 7(1):134-148

Mogaji KA, Lim HS, Abdullah K (2014) Modeling groundwater vulnerability prediction using geographic information system (GIS)-based ordered weighted average (OWA) method and DRASTIC model theory hybrid approach. Arab J Geosci. https ://doi.org/10.1007/s12517-013-1163-3

Mogaji KA, Omosuyi GO, Adelusi AO, Lim HS (2016) Application of GIS-based evidential belief function model to regional groundwater recharge potential zones mapping in hardrock geologic terrain. Environ Process 3(1):2016

Murthy KSR (2000) Groundwater potential in a semi-arid region of Andhra Pradesh: a GIS approach. Int J Remote Sens 21(9): 1867-1884

Nadi S, Delavar MR (2011) Multi-criteria, personalized route planning using quantifier-guided ordered weighted averaging operators. Int J Appl Earth Observ Geoinf. https://doi.org/10.1016/j. jag.2011.01.003

Naghibi SA, Pourghasemi HR, Pourtaghie ZS, Rezaei A (2014) Groundwater qanat potential mapping using frequency ratio and Shannon's entropy models in the Moghan watershed, Iran. Earth Sci Inf. https://doi.org/10.1007/s12145-014-0145-7

Naqa A, Hammouri N, Kuisi M (2006) GIS-based evaluation of groundwater vulnerability in the Russeifa area, Jordan. Revista Mexicana de Ciencias Geologicas 23(3):277-287

Naser T, Omid R, Farhad N, Lee S (2016) Spatial analysis of groundwater potential using weights-of-evidence and evidential belief function models and remote sensing. Arab J Geosci 9:79. https ://doi.org/10.1007/s12517-015-2166-z

National Research Council (1993) Ground water vulnerability assessment, contamination potential under conditions of uncertainty. National Academy Press, Washington DC

Nerantzis K, Konstantinos SV (2015) Groundwater vulnerability and pollution risk assessment of porous aquifers to nitrate: modifying the DRASTIC method using quantitative parameters. J Hydrol 525:13-25

Neshat A, Pradhan B, Dadras M (2014) Groundwater vulnerability assessment using an improved DRASTIC method in GIS. Resour Conserv Recycl 86:74-86

Nobre RCM, Rotunno Filho OC, Mansur WJ, Cosenza CAN, Nobre MMM (2007) Groundwater vulnerability and risk mapping using GIS, modeling and a fuzzy logic tool. J Contam Hydrol 94:277-292

Pacheco FAL, Sanches Fernandes LF (2012) The multivariate structure of DRASTIC model. J Hydrol. https://doi.org/10.1016/jhydr ol.2012.11.20

Panagopoulos GP, Antonakos AK, Lambrakis NJ (2006) Optimization of the DRASTIC method for groundwater vulnerability assessment via the use of simple statistical methods and GIS. Hydrogeol J 14:894-911. https://doi.org/10.1007/s10040-005-0008-x

Pathak G, Iqba J, Gorai AK, Katpata YB (2014) Development of GIS-based fuzzy pattern recognition model (modified DRASTIC model) for groundwater vulnerability to pollution assessment. Int J Environ Sci Technol. https://doi.org/10.1007/s13762-014-0693-x

Pearson K (1900) On the criterion that a given system of deviations from the probable in the case of a correlated system of variables is such that it can be reasonably supposed to have arisen from random sampling. Philos Magn 5(50):157-175 [reprinted in K Pearson (1956), pp 339-357]

Plymale CL, Angle MP (2002) Groundwater pollution potential of Fulton County, Ohio. Ohio Department of Natural Resources Division of Water, Water Resources Section. Groundwater Pollution Potential, Report No. 45

Pradhan B, Neshat A, Pirasteh S, Shafri HZM (2013) Estimating groundwater vulnerability to pollution using a modified
DRASTIC model in the Kerman agricultural area Iran. Environ Earth Sci. https://doi.org/10.1007/s12665-013-2690-7

Qi SL, Gurdak JJ (2006) Percentage of probability of nonpoint source nitrate contamination of recently recharged ground water in the High Plains aquifer: U.S. Geological Survey Data Series. http:// water.usgs.gov/lookup/getspatial?ds192_hp_npctprob. Accessed 14 June 2013

Rahman Atiqur (2008) A GIS based DRASTIC model for assessing groundwater vulnerability in shallow aquifer in Aligarh, India. Appl Geogr 28:32-53. https://doi.org/10.1016/j.apgeo g.2007.07.00832-53

Rahmati O, Pourghasemi HR, Melesse AM (2016) Application of GISbased data driven random forest and maximum entropy models for groundwater potential mapping: a case study at Mehran Region, Iran. CATENA 137(2016):360-372

Razandi Y, Pourghasemi HR, Neisani NS, Omid R (2015) Application of analytical hierarchy process, frequency ratio, and certainty factor models for groundwater potential mapping using GIS. Earth Sci Inf. https://doi.org/10.1007/s12145-015-0220-8

Rinner C, Raubal M (2004) Personalized multi-criteria decision strategies in location-based decision support. Geogr Inf Sci 10(2):149-156

Sadeghfam S, Yousef H, Nadiri AA, Zarghami M (2016) Localization of groundwater vulnerability assessment using catastrophe theory. Water Resour Manage 30(13):4585-4601

Sahoo M, Sahoo S, Dhar A, Pradhan B (2016) Effectiveness evaluation of objective and subjective weighting methods for aquifer vulnerability assessment in urban context. J Hydrol Part B 541:1303-1315

Samake M, Tang Z, Hlaing W, Ndoh MI, Kasereka K, Waheed OB (2011) Groundwater vulnerability assessment in shallow aquifer in Linfen Basin, Shanxi Province, China using DRASTIC model. Int J Sustain Dev 4(1):53

Singh A, Srivastav SK, Kumar S, Chakrapani GJ (2015) A modifiedDRASTIC model (DRASTICA) for assessment of groundwater vulnerability to pollution in an urbanized environment in Lucknow. Environ Earth Sci, India. https://doi.org/10.1007/s1266 5-015-4558-5

Snedecor GW, Cochran WC (1980) Correlation. Statistical methods, 6th edn. The Iowa State University Press, Ames, pp 171-198

Thirumalaivasan D, Karmegam M, Venugopal K (2003) AHPDRASTIC: software for specific aquifer vulnerability assessment using DRASTIC model and GIS. Environ Model Softw 18:645-656. https://doi.org/10.1016/S1364-8152(03)00051-3

Van Stemproot D, Evert L, Wassenaar L (1993) Aquifer vulnerability index: a GIS compatible method for groundwater vulnerability mapping. Can Water Resour J 18:25-37

Wang J, He J, Chen H (2012) Assessment of groundwater contamination risk using hazard quantification, a modified DRASTIC model and groundwater value, Beijing Plain, China. Sci Total Environ 432:216-226

WHO (2004) Guidelines for drinking water quality, vol 1, 3rd edn. WHO, Geneva, p 515

Yager RR (1988) On ordered weighted averaging aggregation operators in multi-criteria decision making. Syst Man Cybern IEEE Trans 18(1):183-190

Yager RR (1996) Quantifier guided aggregation using OWA operators. Int J Intell Syst 11(1):49-73

Yuan M, Zhang X, Wang L (2006) Fuzzy pattern recognition method for assessing groundwater vulnerability to pollution in the Zhangji area. J Zhejiang Univ Sci A 7(11):1917-1922

Publisher's Note Springer Nature remains neutral with regard to jurisdictional claims in published maps and institutional affiliations. 